Check for updates

Cite this: RSC Adv., 2019, 9, 3625

Received 9th November 2018 Accepted 7th January 2019

DOI: $10.1039 / c 8 r a 09275 c$

rsc.li/rsc-advances

\section{Development and application of novel bio- magnetic membrane capsules for the removal of the cationic dye malachite green in wastewater treatment $\uparrow$}

\author{
Imran Ali, ${ }^{\text {ab }}$ Changsheng Peng, (D)*abc Iffat Naz, (D)*de Dichu Lin, ${ }^{\text {ab }}$ \\ Devendra P. Saroj (iD *e and Mohsin Ali $^{f}$
}

Novel bio-magnetic membrane capsules (BMMCs) were prepared by a simple two-step titration-gel crosslinking method using a polyvinyl alcohol (PVA) and sodium alginate (SA) matrix to control the disintegration of phytogenic magnetic nanoparticles (PMNPs) in an aqueous environment, and their performance was investigated for adsorbing cationic malachite green (MG) dye from water. The prepared BMMCs were characterized by FTIR, powder XRD, SEM, EDX, XPS, VSM and TGA techniques. The findings revealed that the hysteresis loops had an excellent superparamagnetic nature with saturation magnetization values of 11.02 $\mathrm{emu}^{-1}$. The prepared BMMCs not only controlled the oxidation of PMNPs but also improved the adsorptive performance with respect to $M G$ dye $\left(500 \mathrm{mg} \mathrm{g}^{-1}\right.$ at $298.15 \mathrm{~K}$ and $\left.\mathrm{pH} 6.5\right)$ due to the presence of a large amount of hydrophilic functional groups (hydroxyl/-OH and carboxyl/-COOH) on/in the BMMCs. The smooth encapsulation of PMNPs into the PVA-SA matrix established additional hydrogen bonding among polymer molecular chains, with improved stability, and adsorptive performance was maintained over a wide range of $\mathrm{pH}$ values (3-12). Importantly, the prepared BMMCs were easily regenerated just by washing with water, and they could be re-utilized for up to four (4) consecutive treatment cycles without observing any apparent dissolution of iron $/ \mathrm{Fe}^{0}$ or damage to the morphology. According to the mass balance approach, an estimated amount of $100 \mathrm{~mL}$ of treated effluent can be obtained from $160 \mathrm{~mL}$ of $\mathrm{MG}$ dye solution (25 $\mathrm{mg} \mathrm{L}^{-1}$ ) just by employing a $0.02 \mathrm{~g} \mathrm{~L}^{-1}$ adsorbent dosage. Finally, a model of BMMCs based on zeroeffluent discharge was also proposed for commercial or industrial applications. The prepared BMMCs are greatly needed for improving the water/wastewater treatment process and they can be utilized as an excellent adsorbent to remove cationic pollutants for various environmental applications.

\section{Introduction}

Toxic dyes in wastewater are considered to be the most primitive pollutants due to their acute toxicity, carcinogenicity, visible

\footnotetext{
${ }^{a}$ The Key Lab of Marine Environmental Science and Ecology, Ministry of Education, Ocean University of China, Qingdao 266100, China. E-mail: pcs005@ouc.edu.cn; Tel: +8653266782011

${ }^{b}$ Department of Environmental Engineering, College of Environmental Science and Engineering, Ocean University of China, Qingdao 266100, China

'School of Environmental and Chemical Engineering, Zhaoqing University, Zhaoqing 526061, China

${ }^{d}$ Department of Biology, Qassim University, Buraidah 51452, Kingdom of Saudi Arabia. E-mail: iffatkhattak@yahoo.com; I.Majid@qu.edu.sa; Tel: +966533897891

${ }^{e}$ Department of Civil and Environmental Engineering, Faculty of Engineering and Physical Sciences, University of Surrey, Surrey GU2 7XH, UK. E-mail: d.saroj@ surrey.ac.uk; Tel: +44 (0)1483-686634

${ }^{f}$ Department of Environmental Engineering, Middle East Technical University, Ankara 0600, Turkey
}

$\dagger$ Electronic supplementary information (ESI) available. See DOI: $10.1039 / \mathrm{c} 8 \mathrm{ra} 09275 \mathrm{c}$ color, complex molecular structure and synthetic origin. Toxic dyes create alarming threats to aquatic environments, destroying the ecological balance and are released from different industries: i.e. paper coloring, cosmetics, dyes fabrication, textiles, mining, electroplating, pharmaceuticals and leather tanning. ${ }^{1-5}$ Among these, textile industries are largely using toxic dyes for coloring their products and about 0.7 million tonnes of toxic dyes are being produced annually, which contain highly hazardous chemicals and byproducts. Approximately $200 \mathrm{~L}$ of water is being used for the production of one kg of textile product. ${ }^{6-10}$ Furthermore, various types of diseases (i.e. heart defects, allergies, skin irritation, jaundice and tumors) are spreading in residential communities by the discharge of toxic dyes into aquatic environments. ${ }^{11,12}$ Hence, the treatment of these hazardous dyes is an imperative area of research for water/wastewater treatment experts to maintain a green and healthy environment.

Currently, multifarious methods (i.e., coagulation, ionexchange, chemical precipitation, flocculation, bioreactors, photo-catalytic degradation, trickling filters, electrochemical 
oxidation, activated sludge, adsorption and membrane filtration) have been developed and somehow optimized to treat toxic dyes from water/wastewater. ${ }^{13,14}$ Despite this dedication, there is still a demand to remove these hazardous dyes, because most of the tested technologies are not environmentally friendly and are expensive. ${ }^{15,16}$ Among them, adsorption is considered comparatively superior in terms of high efficiency, low cost, easy installation and easy operation over other technologies. ${ }^{17-20}$ In the past, a variety of adsorbents have been utilized to remove different kinds of toxic dyes, including agricultural waste material (rice husk, pinewood, orange peel, peanut hull, banana pith and jute fiber), red mud, cellulose, zeolite, ion-exchange resins, activated carbon, clay, chitosan, graphene oxide (GO) and its composites/ derivatives, and so forth. ${ }^{21}$ However, some specific issues (low kinetics, poor stability, low removal performance, nonenvironmental friendliness and lack of reusability) are hampering its employment for commercial applications. ${ }^{22}$

Currently nanotechnology is gaining much attention for the preparation of nanoparticles (NPs) for overcoming these issues. A variety of fabrication protocols (sol-gel, chemical coprecipitation, electrochemical, ball milling, hydrothermal, micro-emulsion, green/bio-reduction, etc.) have been developed and implemented. Among them, bio-reduction is comparatively better for the fabrication of NPs from various kinds of biomaterials for the removal of toxic dyes and the recovery of metal ions from wastewater. Mostly green magnetic nanoparticles (MNPs) have been utilized at lab-scale to remove toxic dyes and metal ions from wastewater. ${ }^{17-20}$ However, MNPs are showing low removal performance, low adsorptive capacity and poor stability for long-term applications due to their oxidation in water treatment. Thus, these disadvantages have hampered the transfer of green nanotechnology from the lab-scale to the commercial scale and various kinds of coating technologies have been used to improve the stability, but they could not enhance the adsorptive capacity. ${ }^{23}$ To overcome these problems, some techniques like encapsulation, loading, embedding and assembling of NPs into different materials have been reported by various investigators. In most of the reported studies, MNPs have been loaded or inserted into different kinds of materials (graphene oxide (GO), chitosan, $\beta$-cyclodextrin/poly(acrylic acid), sodium alginate (SA), poly(vinyl alcohol) (PVA), etc.) to enhance their stability and removal performance. ${ }^{\mathbf{1 6}}$ However, as yet there is no report available to address the encapsulation of green MNPs into these materials.

Therefore, the aim of the present research is the introduction of a novel approach to fabricate bio-magnetic membrane capsules (BMMCs) after the encapsulation of green MNPs into a PVA-SA matrix by using primary and secondary cross-linking agents via a simple titration gel cross-linking method. The following core objectives were designed in order to achieve the aim of the research: (i) fabrication of novel BMMCs to control the disintegration of PMNPs for the possible adsorptive removal of a cationic toxic dye, i.e. malachite green (MG); (ii) confirmation of the smooth encapsulation of PMNPs and characterization of BMMCs by employing different techniques, i.e. FTIR, powder XRD, SEM, EDX, XPS, TGA and VSM; (iii) assessment of the influence of various operational parameters, including the amount of PMNP encapsulation, adsorbent/BMMC dosages, solution $\mathrm{pH}$, temperature, contact time, initial concentration of MG dye and co-existing ions, on the adsorptive performance of BMMCs; (iv) observation of the adsorptive performance of BMMCs in terms of sorption capacity and sorption kinetics; (v) engagement of various isotherms, kinetics and thermodynamic equations for scrutinizing probable removal mechanisms; and (vi) finally, the development of an appropriate regeneration scheme and consequent determination of the potential for reusability of BMMCs for consecutive treatment cycles.

\section{Materials and methods}

\subsection{Materials/chemicals and instrumentation}

The details of the chemicals and instrumentations used in the present study are documented in the ESI (Text-SI $\dagger$ ). In addition, the molecular structure and chemical properties of the malachite green (MG) dye are also provided in Table SI. $\dagger$

\subsection{Preparation of bio-magnetic membrane capsules (BMMCs)}

BMMCs were prepared via a two-step titration-gel cross-linking method by the cross-linking of PVA and SA solutions using GA, boracic acid $\left(\mathrm{H}_{3} \mathrm{BO}_{3}\right)$ and anhydrous calcium chloride $\left(\mathrm{CaCl}_{2}\right)$ in the presence of PMNPs. PVA powder (10.0 wt $\%$ ) was dissolved in $100 \mathrm{~mL}$ of distilled water and kept at $95{ }^{\circ} \mathrm{C}$ under vigorous stirring at a speed of $150 \mathrm{rpm}$ for at least $24 \mathrm{~h}$, until it was ensured that the mixture was homogenously dissolved. SAPMNPs solution (3.0 wt\%) was prepared by adding $3.0 \mathrm{~g}$ of SA powder into $97 \mathrm{~mL}$ of PMNP solution and heating at $95{ }^{\circ} \mathrm{C}$ under vigorous stirring at a speed of $100 \mathrm{rpm}$ for at least $24 \mathrm{~h}$, so a homogenous suspension was obtained. Meanwhile, a primary cross-linking solution of an oversaturated solution of $\mathrm{CaCl}_{2}$ ( $5 \mathrm{wt} \%$ ) and $\mathrm{H}_{3} \mathrm{BO}_{3}$ was prepared separately by dissolving $25.0 \mathrm{~g}$ of $\mathrm{CaCl}_{2}$ and $20.0 \mathrm{~g}$ of $\mathrm{H}_{3} \mathrm{BO}_{3}$ into $500 \mathrm{~mL}$ of distilled water with the $\mathrm{pH}$ of the mixture maintained at 4 . A secondary crosslinking solution of GA (1 wt $\%$ ) was prepared separately by adding $2 \mathrm{~mL}$ of GA $\left(50 \%\right.$ dissolved in $\left.\mathrm{H}_{2} \mathrm{O}\right)$ into $98 \mathrm{~mL}$ of distilled water. Thereafter, a $4: 1(\mathrm{v} / \mathrm{v})=$ [PVA (10.0 wt $\%):$ SAPMNPs $(3.0 \mathrm{wt} \%)]=20.0 \mathrm{~g}$ PVA : $5.0 \mathrm{~g}$ SA-PMNPs solution was prepared and stirred together for at least $3 \mathrm{~h}$, until a homogenous suspension was obtained, and it was then ultrasonically oscillated for at least $2 \mathrm{~h}$ to further ensure its homogenous quality. After this, the casting solution, i.e. PVA-SA-PMNPs, was transferred into a syringe that had a needle diameter of around about $3.2 \mathrm{~mm}$, and it was placed horizontally in a syringe pump by adjusting the feed flow rate to $13 \mathrm{~mL} \mathrm{~h}^{-1}$. Then, the mixture droplet was injected into the primary cross-linking solution via a syringe pump by keeping a distance of $8 \mathrm{~cm}$ between the needle tip and the primary cross-linking agent solution surface. The prepared capsules were kept in the primary cross-linking agent solution for at least $24 \mathrm{~h}$ to form PMNP globules, then gently separated from the primary cross-linking agent solution and were shifted into the secondary cross-linking agent solution for at least $8 \mathrm{~h}$. Thereafter, the prepared PMNPs were separated and washed thoroughly five to six times with distilled water 
until $\mathrm{pH}=7$ and stored for further experimental studies. A schematic of BMMC fabrication is illustrated in Fig. 1.

Moreover, for the investigation of the influence of PMNP encapsulation on the removal performance, various types of BMMCs were also prepared by encapsulating different amounts of PMNPs ( 1 to $5 \mathrm{wt} \%$ ) into the PVA-SA matrix.

SA solution (3.0 wt\%) was prepared by adding $3.0 \mathrm{~g}$ of SA powder into $100 \mathrm{~mL}$ of distilled water and heated at $95^{\circ} \mathrm{C}$ under vigorous stirring at a speed of $100 \mathrm{rpm}$ for at least $24 \mathrm{~h}$, and finally a homogenous suspension was obtained. Furthermore, an SA-PMNPs solution was prepared by incorporating different amounts of PMNPs ( 1 to $5 \mathrm{wt} \%$ ) and heated at $95{ }^{\circ} \mathrm{C}$ under vigorous stirring at a speed of $100 \mathrm{rpm}$ for at least $24 \mathrm{~h}$, until finally a homogenous suspension was obtained. For the fabrication of these capsules, $4: 1(\mathrm{v} / \mathrm{v})=$ PVA-[SA-PMNPs] solutions were prepared as displayed in Table 1 , and then the capsules were prepared according to the same procedure, as previously illustrated in Fig. 1.

\subsection{Characterization of BMMCs}

2.3.1. Physical properties/micromeritic studies. For the micromeritic studies, the diameter of the prepared BMMCs was determined by a Vernier caliper ( $n=100$, MNT-150, Shanghai, China). Initially, the shape of the prepared BMMCs was estimated by measuring the aspect ratio of the capsules. The aspect ratio of the prepared capsules was calculated as:

$$
\text { Aspect ratio }=\frac{D_{\max }}{D_{\min }}
$$

where $D_{\max }\left(\mathrm{mm} \mathrm{m}^{-1} \mathrm{~cm}^{-1}\right)$ and $D_{\min }\left(\mathrm{mm} \mathrm{m}^{-1} \mathrm{~cm}^{-1}\right)$ are the maximum and minimum diameters of the prepared capsules, respectively. For this purpose, fifteen (15) specimen capsules were randomly selected from the prepared BMMCs. The values closer to one (1), a rounder shape, suggested a perfect sphere shape for the capsules. Moreover, the density $(P)$ of the prepared capsules was determined and calculated by using following equations:

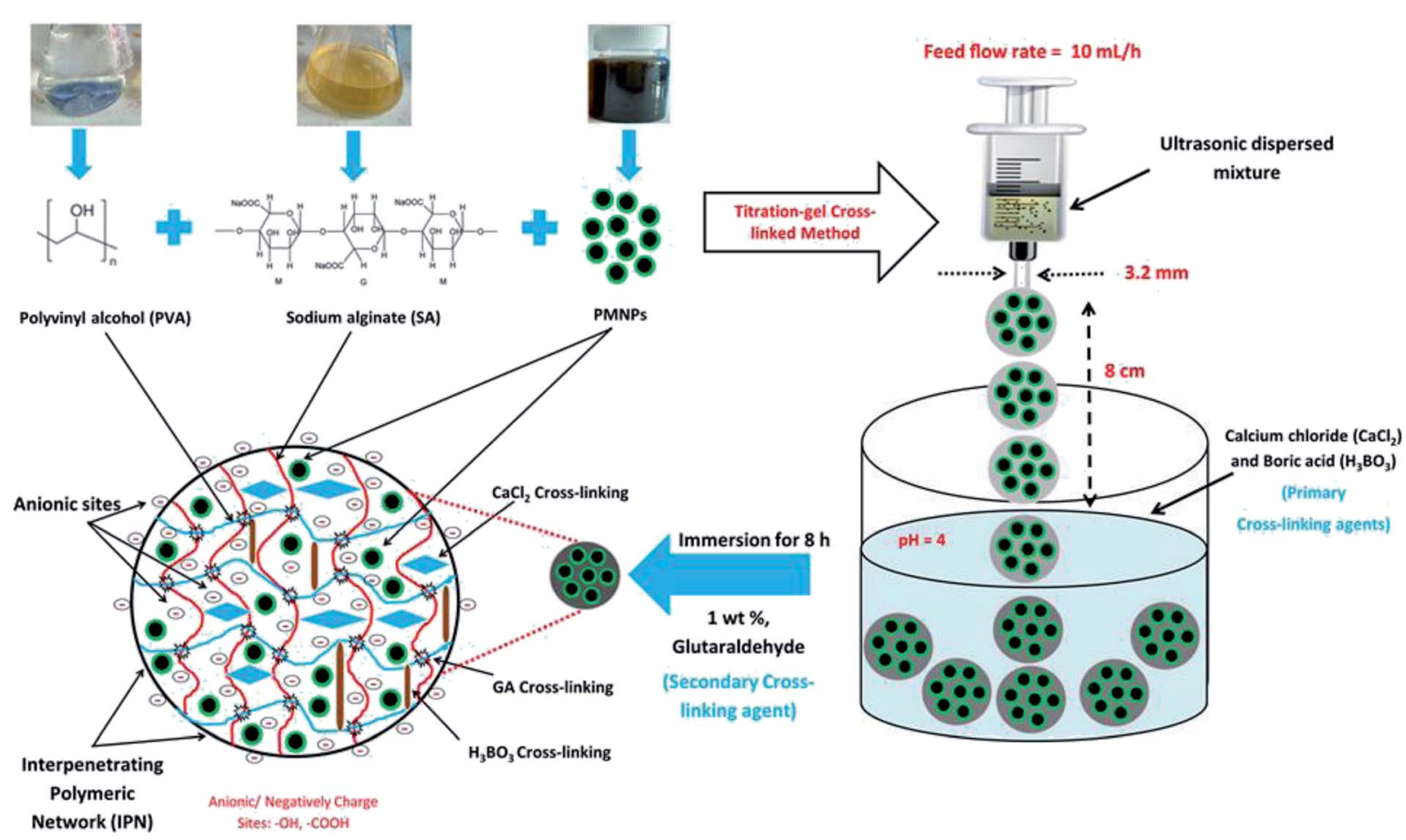

Fig. 1 A schematic diagram of bio-magnetic membrane capsule (BMMC) fabrication by the encapsulation of phytogenic magnetic nanoparticles (PMNPs). (Reproduced from Ali et al. ${ }^{24}$ Copyright@2019, with permission from Elsevier Ltd.)

Table 1 Experimental procedure to fabricate various types of bio-magnetic membrane capsules (BMMCs) by the encapsulation of different amounts of phytogenic magnetic nanoparticles (PMNPs)

\begin{tabular}{lllll}
\hline PMNPs & Amount of PMNPs $^{a}(\mathrm{~g})$ & PVA $(\mathrm{g})$ & SA (g) & $4: 1(\mathrm{v} / \mathrm{v})=$ PVA-[SA-PMNPs] \\
\hline $1.0 \mathrm{wt} \%$ & $2.15 \times 1 \%=0.215$ & 20 & 4.785 & $20 / 4.785+0.215$ \\
$2.0 \mathrm{wt} \%$ & $2.15 \times 2 \%=0.430$ & 20 & 4.570 & $20 / 4.570+0.430$ \\
$3.0 \mathrm{wt} \%$ & $2.15 \times 3 \%=0.645$ & 20 & 4.355 & $20 / 4.355+0.645$ \\
$4.0 \mathrm{wt} \%$ & $2.15 \times 4 \%=0.860$ & 20 & 4.140 & $20 / 4.140+0.860$ \\
$5.0 \mathrm{wt} \%$ & $2.15 \times 5 \%=1.075$ & 20 & 3.925 & $20 / 3.925+1.075$
\end{tabular}

${ }^{a} \mathrm{PVA}: \mathrm{SA}=4[10 \mathrm{wt} \%]=1[3 \mathrm{wt} \%]$; if PVA $=20 \mathrm{~g}$ then $\mathrm{SA}=5 \mathrm{~g}$; thus, the total mass of the whole polymer: $20 \times 10 \%+5 \times 3 \%=2.15 \mathrm{~g}$. 


$$
\begin{aligned}
& \text { Density, } P\left(\mathrm{~g} \mathrm{~m}^{-3}\right)=\frac{M}{V} \\
& \text { Volume, } \quad V\left(\mathrm{~m}^{3}\right)=\frac{4 \pi r^{3}}{3}
\end{aligned}
$$

where $P, M, V$ and $r$ are the density $\left(\mathrm{g} \mathrm{m}^{-3}\right)$, weight (g), volume $\left(\mathrm{m}^{3}\right)$ and radius of the prepared BMMCs, respectively. Furthermore, the density of the prepared capsules was measured by calculating their weight both on a wet basis and a dry basis. In addition, the theoretical average water content/swelling ratio (SR) of the prepared BMMCs was also estimated by using following equations:

$$
\text { Water content/swelling ratio }(\%)=((W-D)) / W \times 100 \%
$$

where $W$ and $D$ are the average weight of BMMCs on a wet and dry basis, respectively, as calculated by a digital analytical weighing balance (Sartorius Entris 64-1S, German).

2.3.2. Morphology and identification of functional groups of the prepared BMMCs. For the investigation of morphology and functional groups, a field emission-scanning electron microscope was used to scrutinize the morphology of the prepared BMMCs from the outer surface to the inner core at 5 $\mathrm{kV}$. First, the fabricated BMMCs were dipped in liquid nitrogen for $2 \mathrm{~min}$, and then freeze dried at $-80{ }^{\circ} \mathrm{C}$ and $10 \mathrm{~Pa}$ for $72 \mathrm{~h}$ to obtain a perfect hydrogel skeleton. The chemical composition and functional groups of the prepared BMMCs were investigated using FTIR, with a resolution of $4 \mathrm{~cm}^{-1}$, scans $=64$ and wavelength in the range of $650-4000 \mathrm{~cm}^{-1}$. For FTIR analysis, four types of samples were prepared: (i) a PVA-SA mixture was prepared by homogenously mixing of $4 \mathrm{~mL}$ of PVA and $1 \mathrm{~mL}$ of SA solution together, and then dried in a hot oven at $95{ }^{\circ} \mathrm{C}$ for at least $4 \mathrm{~h}$. After this, the dried sample was ground to convert it into powder; (ii) a PVA-SAPMNP mixture was prepared by mixing $4 \mathrm{~mL}$ of PVA, $1 \mathrm{~mL}$ of $\mathrm{SA}$, and $2 \mathrm{~mL}$ of PMNP solution together, and then drying in a hot oven at $95^{\circ} \mathrm{C}$ for at least $4 \mathrm{~h}$. After this, the dried sample was ground to convert it into powder; (iii) BMMCs were prepared without incorporating secondary cross-linking agents and freeze dried at $-80{ }^{\circ} \mathrm{C}$ and $10 \mathrm{~Pa}$ for $72 \mathrm{~h}$, then these were ground to convert them into powder; and (iv) finally, BMMCs were prepared by incorporating primary and secondary cross-linking agents and freeze dried at $-80{ }^{\circ} \mathrm{C}$ and $10 \mathrm{~Pa}$ for $72 \mathrm{~h}$, and then these were ground to convert them into powder.

\subsection{Surface properties, elemental contents, thermal stability and magnetic measurements of the prepared BMMCs}

EDX and XPS were employed to detect the elemental contents and atomic percentages of the prepared BMMCs. The thermal stability of the prepared BMMCs was investigated using TGA, and nitrogen $\left(\mathrm{N}_{2}\right)$ gas was used to perform TGA analysis. Material properties and magnetic measurements were conducted by XRD and VSM. The material interlayer spacing was estimated based on Bragg's Law and freeze-dried BMMCs were utilized to accomplish all these analyses.

\subsection{Adsorption and desorption experimental studies}

All the experiments were conducted in batch mode by shaking Erlenmeyer flasks in a rotary shaker at $100 \mathrm{rpm}$ under atmospheric pressure and room temperature $\left(25 \pm 2{ }^{\circ} \mathrm{C}\right)$. A fixed amount of the prepared freeze-dried BMMCs was added into $40 \mathrm{~mL}$ of MG dye solution with concentrations ranging from 25 to $1000 \mathrm{mg} \mathrm{L}^{-1}$ and the $\mathrm{pH}$ of the dye solution was maintained at 6.5. The initial MG dye concentration was $25 \mathrm{mg} \mathrm{L}^{-1}$, and the $\mathrm{pH}$ of the MG dye solution was kept stable at 6.5 throughout all the experiments. For the sorption isotherm and kinetic studies, a fixed amount of $0.02 \mathrm{~g} \mathrm{~L}^{-1}$ BMMCs was immersed into $40 \mathrm{~mL}$ of MG dye solution (25-1000 $\left.\mathrm{mg} \mathrm{L}^{-1}\right)$ at $\mathrm{pH} 6.5$ and it was kept in a temperature-controlled rotary shaker under atmospheric pressure and room temperature $\left(25 \pm 2{ }^{\circ} \mathrm{C}\right)$ at $100 \mathrm{rpm}$. Then, it was allowed to react with the prepared BMMCs for 0-96 h and the final MG dye concentration was observed at the end of 2, 5 , $8,10,15,20,24,30,36,40,48,64,72$ and $96 \mathrm{~h}$ by a UV-vis spectrophotometer. The BMMCs were separated from the final solution using a simple hand-held magnet at the end of each experiment. A UV-vis spectrophotometer was utilized to detect the final MG dye concentration and the sample absorbance readings were determined at $\lambda_{\max }=617 \mathrm{~nm}$ for MG. Predetermined standard calibration curves were employed to calculate the real values. All the tests were carried out in triplicate and the averaged values were used to obtain the real concentration. Finally, the removal efficiency and adsorptive capacity at different time intervals and at equilibrium were calculated using the following equations:

$$
\begin{gathered}
\text { Removal efficiency }(\%)=\frac{C_{\mathrm{o}}-C_{\mathrm{t}}}{C_{\mathrm{o}}} \times 100 \% \\
\text { Adsorption amount, } q_{\mathrm{e}}\left(\mathrm{mg} \mathrm{g}^{-1}\right)=\frac{\left(C_{\mathrm{o}}-C_{\mathrm{e}}\right) V}{M}
\end{gathered}
$$

where $C_{\mathrm{o}}\left(\mathrm{mg} \mathrm{L}^{-1}\right)$ is the initial MG dye concentration in solution, $C_{\mathrm{t}}\left(\mathrm{mg} \mathrm{L}^{-1}\right)$ is the final MG dye concentration in solution at different time intervals, $C_{\mathrm{e}}\left(\mathrm{mg} \mathrm{L}^{-1}\right)$ is the concentration of MG dye in solution at time equilibrium, $M(\mathrm{~g})$ is the amount of BMMCs and $V(\mathrm{~L})$ is the volume of MG dye solution.

To investigate the probable removal mechanism of MG dye by the prepared BMMCs, the experimental data were further fitted into different isotherm models (Langmuir, Freundlich, Temkin and Dubinin-Radushkevich) and kinetics models (i.e. pseudo-first-order, pseudo-second-order, Elovich, intraparticle diffusion and liquid film diffusion) (Text-SII $\dagger$ ). The debate was conducted after calculating the values of the regression coefficient $\left(R^{2}\right)$. In addition, thermodynamic parameters (i.e. change in free energy $\Delta G^{\circ}\left(\mathrm{kJ} \mathrm{mol}^{-1}\right)$, enthalpy $\Delta H^{\circ}\left(\mathrm{kJ} \mathrm{mol}^{-1}\right)$ and entropy $\left.\Delta S^{\circ}\left(\mathrm{kJ} \mathrm{mol}^{-1}\right)\right)$ were also estimated at 298.15, $303.15,313,323.15$ and $333.15 \mathrm{~K}$ in a temperature-controlled rotary shaker at $100 \mathrm{rpm}$ by employing a $0.02 \mathrm{~g} \mathrm{~L}^{-1}$ adsorbent dose at an initial MG dye concentration of $25 \mathrm{mg} \mathrm{L}^{-1}$ under atmospheric pressure and room temperature $\left(25 \pm 2{ }^{\circ} \mathrm{C}\right)$ (Text$\mathrm{SII} \dagger)$.

2.5.1. Effect of co-present constituents on the adsorptive removal of MG dye by the prepared BMMCs. The existence of copresent constituents can create competition to remove targeted 
pollutants during the adsorption process. The presence of heavy metal ions $\left(\mathrm{Pb}^{2+}\right.$ and $\left.\mathrm{Cd}^{2+}\right)$ in textile wastewater is often reported and these ions can create selectivity in the removal of cationic MG dye. For this purpose, two binary systems, i.e. (i) $\mathrm{MG}$ dye $+\mathrm{Pb}^{2+}$ and (ii) $\mathrm{MG}$ dye $+\mathrm{Cd}^{2+}$, were designed by keeping the MG dye concentration stable $\left(25 \mathrm{mg} \mathrm{L}^{-1}\right)$ and the concentrations of $\mathrm{Pb}^{2+}$ and $\mathrm{Cd}^{2+}$ were varied as $1,5,25,50,100$, $1000 \mathrm{mg} \mathrm{L}^{-1}$. A fixed amount of $0.02 \mathrm{~g} \mathrm{~L}^{-1}$ adsorbent dose was added into $40 \mathrm{~mL}$ of binary solution containing $\mathrm{Pb}^{2+}$ and $\mathrm{Cd}^{2+}$ and the MG dye $\left(25 \mathrm{mg} \mathrm{L}^{-1}\right)$ and the $\mathrm{pH}$ was maintained at 6.5. The mixture was allowed to react with the prepared BMMCs for $24 \mathrm{~h}$ and then the final MG dye concentration was noted.

\subsection{Regeneration and reusability of BMMCs}

2.6.1. Selection of regeneration solution. To select a suitable regeneration solution, various types of regeneration solutions of different concentrations (methanol: 25 to $100 \%$; $\mathrm{NaOH}$ : 0.5 to $3 \mathrm{M}$; HCl: 25 to $100 \%$; NaCl: 0.5 to $3 \mathrm{M}$; EDTA: 0.025 to $2 \mathrm{M} ; \mathrm{H}_{2} \mathrm{O}: 10-50 \mathrm{~mL}$ and combination of $1 \mathrm{M} \mathrm{NaCl}$ in methanol solution: 25 to $100 \%$ ) were utilized. Initially, the MG dye was sorbed onto the surface of the prepared BMMCs by adding a fixed amount of $0.02 \mathrm{~g} \mathrm{~L}^{-1}$ adsorbent dose in $40 \mathrm{~mL}$ of MG dye solution $\left(25 \mathrm{mg} \mathrm{L}^{-1}\right)$. Then, after approaching equilibrium (24 h), different kinds of regeneration solutions were utilized to observe the desorption capability. The following equations were used to measure the adsorption-desorption efficiencies:

$$
\begin{aligned}
& \text { Adsorption efficiency }(\%)=\frac{C_{\mathrm{o}}-C_{\mathrm{e}}}{C_{\mathrm{o}}} \times 100 \% \\
& \text { Desorption efficiency, } \eta(\%)=\frac{M_{\text {desorbed }}}{M_{\text {sorbed }}} \times 100 \% \\
& =\frac{\left(C_{\mathrm{r}} \times V_{\mathrm{r}}\right)}{\left(C_{\mathrm{o}}-C_{\mathrm{e}}\right) \times V} \times 100 \%
\end{aligned}
$$

where $M_{\text {desorbed }}$ is the quantity of MG dye sorbed onto BMMCs, $M_{\text {sorbed }}$ is the amount of MG dye desorbed from the biomagnetic membrane capsules, $C_{\mathrm{o}}\left(\mathrm{mg} \mathrm{L}^{-1}\right)$ is the initial $\mathrm{MG}$ dye concentration in the feed solution, $C_{\mathrm{e}}\left(\mathrm{mg} \mathrm{L}^{-1}\right)$ is the $\mathrm{MG}$ dye concentration at equilibrium, $V(\mathrm{~L})$ is the volume of feed solution, $C_{\mathrm{r}}\left(\mathrm{mg} \mathrm{L}^{-1}\right)$ is the $\mathrm{MG}$ dye concentration in solution after regeneration and $V_{\mathrm{r}}$ is the volume of regeneration solution.

2.6.2. Optimization of feed-to-regeneration ratio. For the optimization of the feed-to-regeneration ratio (v/v), $0.02 \mathrm{~g} \mathrm{~L}^{-1}$ of the prepared BMMCs was added into $40 \mathrm{~mL}$ of MG dye solution (25 $\mathrm{mg} \mathrm{L}^{-1}$ ) and then desorption was conducted by adding different volumes of regeneration solution (Table 2).

2.6.3. Sorption and desorption cyclic study. To determine the prepared BMMCs' stability and reusability for long-term applications, the MG dye sorption-desorption potential of the BMMCs was examined for up to ten consecutive treatment cycles. First, an amount of $0.02 \mathrm{~g} \mathrm{~L}^{-1}$ of BMMCs was added into $40 \mathrm{~mL}$ of MG dye solution (25 $\mathrm{mg} \mathrm{L}^{-1}$ ) to adsorb MG ions for a time period of $24 \mathrm{~h}$. In each cycle, the capsules were separated by using a magnet and subsequently added into $15 \mathrm{~mL}$ of distilled water and cleaned completely for at least $10 \mathrm{~h}$. Then, it was re-employed for the sorption of MG dye. The adsorptiondesorption efficiencies were estimated using eqn (7) and (8).

\section{Results and discussion}

\subsection{Physical properties of the bio-magnetic membrane capsules (BMMCs)}

Table 3 illustrates the physical properties of the prepared BMMCs. According to the aspect ratio values, the prepared BMMCs were close to a perfect sphere. Other parameters such as diameter, weight and density were also estimated both on a wet and a freeze-dried basis. These findings suggest that the BMMCs could hold approximately $90 \%$ water content due to the presence of enriched hydrophilic functional groups. On average, the diameter of the prepared BMMCs was $4 \pm 0.02 \mathrm{~mm}$ (Fig. SI†).

Table 3 Physical properties/micromeritic results of the prepared biomagnetic membrane capsules (BMMCs)

\begin{tabular}{llc}
\hline Parameters & Unit & \multicolumn{1}{l}{ Values } \\
\hline Average wet weight/capsule & $\mathrm{g}$ & $0.064 \pm 0.001$ \\
Average freeze dried weight/capsule & $\mathrm{g}$ & $0.0062 \pm 0.0001$ \\
Average maximum diameter & $\mathrm{mm}$ & $4 \pm 0.02$ \\
Average minimum diameter & $\mathrm{mm}$ & $3.93 \pm 0.01$ \\
Average density (on wet basis) & $\mathrm{g} \mathrm{m}^{-3}$ & $261.56 \pm 0.05$ \\
Average density (on dry basis) & $\mathrm{g} \mathrm{m}^{-3}$ & $2700 \pm 0.5$ \\
Aspect ratio (on average) & $(-)$ & $1.01 \pm 0.03$ \\
Average water content & $(\%)$ & $90.37 \pm 0.05$
\end{tabular}

Reproduced from Ali et al. ${ }^{24}$ Copyright@2019, with permission from

\begin{tabular}{|c|c|c|c|}
\hline Process & Employed solution & $\begin{array}{l}\text { Regeneration } \\
\text { volume }(\mathrm{mL})\end{array}$ & $\begin{array}{l}\text { Feed-to- } \\
\text { regeneration } \\
\text { ratio }(\mathrm{v} / \mathrm{v})\end{array}$ \\
\hline \multirow{7}{*}{$\begin{array}{l}\text { Sorption-desorption } \\
\text { of MG dye }\end{array}$} & \multirow{7}{*}{$\begin{array}{l}25 \mathrm{mg} \mathrm{L}^{-1} \text { of } \mathrm{MG} \text { dye }(40 \mathrm{~mL}) \text { and } \\
\text { distilled water }\left(\mathrm{H}_{2} \mathrm{O}\right)\end{array}$} & 40 & 1.0 \\
\hline & & 35 & 1.1 \\
\hline & & 30 & 1.3 \\
\hline & & 25 & 1.6 \\
\hline & & 15 & 2.7 \\
\hline & & 10 & 4.0 \\
\hline & & 5 & 8.0 \\
\hline
\end{tabular}
Elsevier Ltd.

Table 2 Experimental conditions to investigate the optimum feed-to-regeneration ratio $(\mathrm{v} / \mathrm{v})$ 


\subsection{Formation mechanism and characterization of BMMCs}

3.2.1. Identification of the functional groups/FTIR analysis. The FTIR analysis of the BMMCs is shown in Fig. 2a. First, the FTIR spectrum of the PVA and SA mixture was studied (Fig. 2a). The results suggested that the hydrophilic functional groups, i.e. $-\mathrm{OH} /$ hydroxyl groups (at 3600-3300 $\mathrm{cm}^{-1}$ ), and carboxyl groups (at 1600-800 $\mathrm{cm}^{-1}$ ) interacted with each other and established a uniform mixture. ${ }^{10}$ The bands at 3600$3300 \mathrm{~cm}^{-1}$ were attributed to $\mathrm{O}-\mathrm{H}$ stretching vibrational peaks of polyphenolic groups and the bands at $3191-2898 \mathrm{~cm}^{-1}$ were attributed to $-\mathrm{C}-\mathrm{H} /-\mathrm{CH}_{2} / \mathrm{CH}_{3}$ stretching vibrational peaks of alkanes. $^{4}$ Moreover, the characteristic peaks appearing at around 1637 and $893 \mathrm{~cm}^{-1}$ indicated $\mathrm{C}=\mathrm{O}$ stretching and the presence of $\mathrm{O}-\mathrm{Na}$ bonds in the $-\mathrm{COONa}$ radical of sodium alginate (SA), respectively. ${ }^{5}$ Furthermore, the peaks at 1562 $1363 \mathrm{~cm}^{-1}$ were assigned to $\mathrm{C}-\mathrm{OH}$ stretching/-COO${ }^{-}$groups of SA. Similarly, the band peak at $1039 \mathrm{~cm}^{-1}$ was assigned to the C-OH stretching of PVA. ${ }^{9}$ Thus, the results of the FTIR spectrum of the PVA-SA mixture showed that the amalgam was homogenous and the hydrophilic functional groups had well interacted with each other via electrostatic forces due to hydrogen bonding. ${ }^{8}$ Similarly, the FTIR spectrum of the PVA-SA-PMNPS mixture was also studied initially to observe the influence of PMNP addition into PVA and SA solution (Fig. 2b). The results indicated that the intensity of the peaks (at $3600-3300 \mathrm{~cm}^{-1}$ ) and (at 3191-2898 $\mathrm{cm}^{-1}$ ) was slightly reduced. This might be due to the space occupied by PMNPs. ${ }^{7}$ An absorption peak appeared at $489 \mathrm{~cm}^{-1}$, which can be assigned to $\mathrm{Fe}-\mathrm{O}$, confirming the existence of PMNPs in the PVA-SA mixture (Fig. 2b). ${ }^{3}$ However, the chemical structure did not change significantly, except that the color of the mixture changed from light yellow to black after inserting the PMNPs solution.

To better understand the formation mechanism of BMMCs, the FTIR spectra of BMMCs were studied after incorporating primary and secondary cross-linking agents (Fig. 2c and d). It was observed that the cross-linking reaction occurred quickly by injecting a casting drop of PVA-SA-PMNPs mixture into

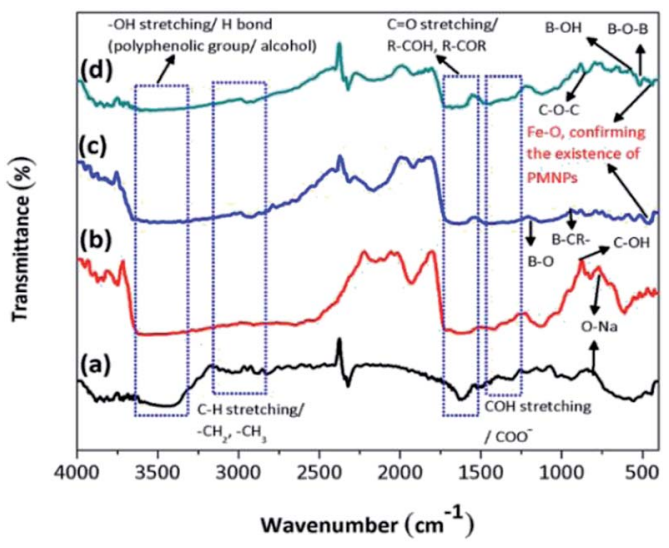

Fig. 2 The Fourier transform infrared (FTIR) spectra of (a) PVA-SA, (b) PVA-SA-PMNPs, (c) PVA-SA-PMNPs after primary cross-linking and (d) fabricated bio-magnetic membrane capsules (BMMCs). (Reproduced from Ali et al. ${ }^{24}$ Copyright@2019, with permission from Elsevier Ltd.) oversaturated $\mathrm{CaCl}_{2}$ and $\mathrm{H}_{3} \mathrm{BO}_{3}$ solution and an interpenetrating polymer network (IPN) structure was developed. 12,16,22 First, a semi-interpenetrating polymer network (SIPN) structure was formed through cross-linking of the G units in the SA chains through $\mathrm{Ca}^{2+}$ via chelation, and covalent and hydrogen bonding in the presence of PVA-PMNPs. ${ }^{14}$ This illustrated that ionic bonding was developed between $\mathrm{Ca}^{2+}$ and the carboxyl groups of SA and partial covalent bonding occurred between $\mathrm{Ca}^{2+}$ and the oxygen atom of the ether groups, respectively. Meanwhile, another SIPN structure was formed through crosslinking of $\mathrm{B}^{3+}$ with PVA via hydrogen bonding in the presence of SA-PMNPs. ${ }^{21}$ It should be noted that $\mathrm{CaCl}_{2}$ and $\mathrm{H}_{3} \mathrm{BO}_{3}$ were continuously utilizing $-\mathrm{OH}$ and -COONa in PVA and SA, and meantime the $\mathrm{B}-\mathrm{O}, \mathrm{B}-\mathrm{CR}$ and $\mathrm{B}-\mathrm{O}-\mathrm{B}$ stretching characteristic peaks appeared at around 1406, 1061 and $696 \mathrm{~cm}^{-1}$ (Fig. 2c). ${ }^{4}$ However, the band of the O-Na bond at $893 \mathrm{~cm}^{-1}$ disappeared or was significantly reduced, suggesting inter/intra hydrogen bonding among PVA, SA and primary cross-linking agents (Fig. 2c). ${ }^{9}$ The characteristic peaks around 1560 and $1480 \mathrm{~cm}^{-1}$ attributed to the anti-symmetric and symmetric stretching vibrational peaks of $-\mathrm{COH} /-\mathrm{COO}^{-}$groups in the polymer network (Fig. 2c), illustrate the formation of an IPN structure. ${ }^{5}$

Further, during secondary cross-linking with GA, both SINP structures of SA and PVA reacted with GA independently and an IPN structure was developed by cross-linking of - $\mathrm{COH}$ groups in GA with - $\mathrm{OH}$ groups in SA and PVA to form acetyls and ether linkages, as shown by mounting characteristic peaks of $\mathrm{C}=\mathrm{O}$, $\mathrm{C}-\mathrm{O}-\mathrm{C}, \mathrm{B}-\mathrm{OH}$ and $\mathrm{B}-\mathrm{O}-\mathrm{B}$ stretching vibrations at around 1666 , 1074, 941 and $640 \mathrm{~cm}^{-1} .8$ This showed that during secondary cross-linking, PVA and SA cross-linked through hydrogen bonding and van der Waals forces, promoting a physical entanglement and chemically cross-linked-3D polymer network in membrane capsules. ${ }^{7}$ Hence, GA performed as a 'knot' or 'joint' to combine SA and PVA together via a co-cross-linking reaction that reinforced the overall mechanical properties of the capsule membranes and made them more beneficial for the adsorption process (Fig. $2 \mathrm{~d}) .{ }^{21}$

On the other hand, a change in the chemical structure in the capsule membrane was not noticeable by FTIR due to the encapsulation of PMNPs, but the characteristic peak can be observed at around $480 \mathrm{~cm}^{-1}$ in both spectra (Fig. 2c and d), suggesting the existence of the smooth encapsulation of PMNPs into the membrane capsules. ${ }^{3}$ The encapsulated PMNPs have their own functional groups $\left(-\mathrm{OH}\right.$ and $\left.-\mathrm{COO}^{-}\right)$, that will also help to increase the anion active sites for the adsorption of cationic pollutants. ${ }^{6}$

In addition, the prepared BMMCs adsorbent can easily be separated from the final effluent just by applying a simple handheld magnet and could be reused for multiple consecutive treatment cycles after regeneration. This encapsulation technique will also help to resolve PMNP disintegration problems and improve the stability of PMNPs. In addition, the functional groups can be maintained for long-term applications. ${ }^{3}$ Altogether, the FTIR results confirmed the smooth formation of BMMCs via chelation, hydrogen bonding and van der Waals forces by employing primary and secondary cross-linking 


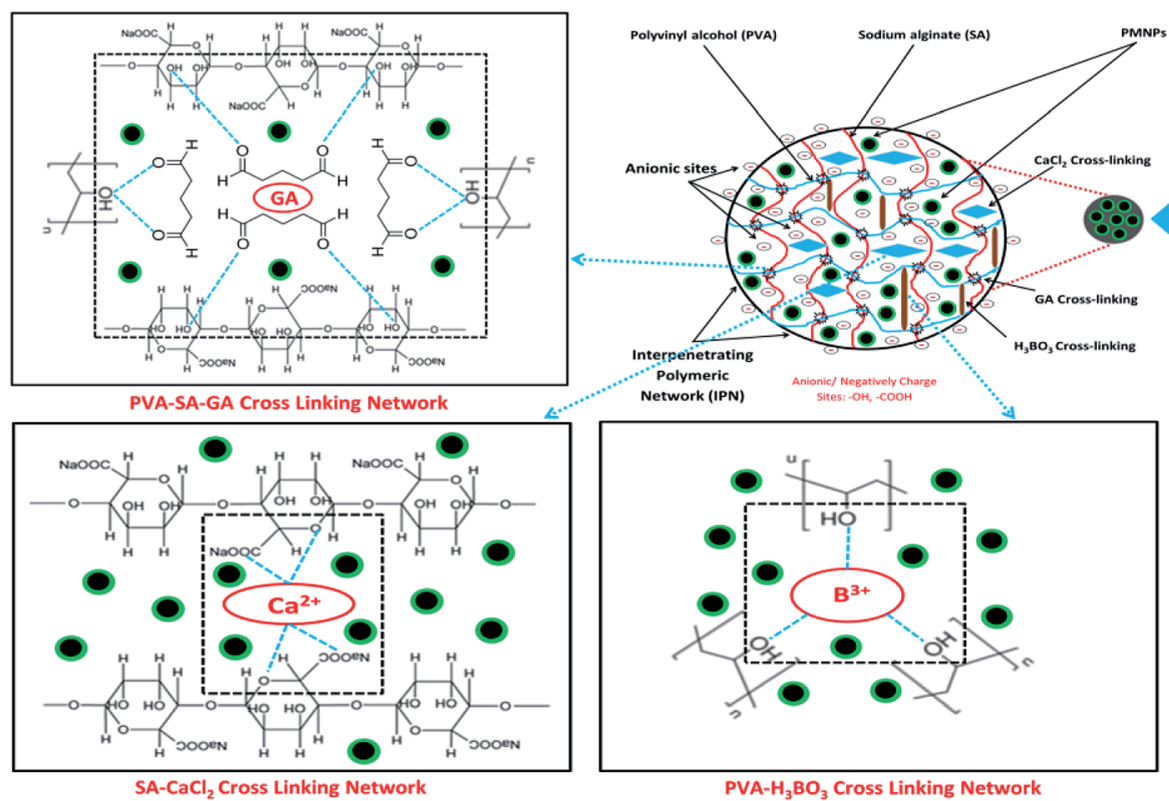

Fig. 3 Conceptual possible cross-linking networks of $\mathrm{SA}-\mathrm{CaCl}_{2}, \mathrm{PVA}-\mathrm{H}_{3} \mathrm{BO}_{3}$ and PVA-SA-GA during the fabrication of bio-magnetic membrane capsules (BMMCs). (Reproduced from Ali et al. ${ }^{24}$ Copyright@2019, with permission from Elsevier Ltd.)

agents. The conceptual possible cross-linking networks of SA$\mathrm{CaCl}_{2}, \mathrm{PVA}-\mathrm{H}_{3} \mathrm{BO}_{3}$ and PVA-SA-GA during the fabrication of BMMCs are shown in Fig. 3.

3.2.2. Powder XRD analysis. The powder XRD patterns of the prepared BMMCs are shown in Fig. 4. First, the XRD pattern of PVA-SA-PMNPs mixture was carried out to investigate the presence and smooth mixing of PMNPs into the PVA-SA matrix (Fig. 4a). The results of the XRD analysis suggest a series of characteristic diffraction peaks emerging at around $2 \theta=30^{\circ}$, $35^{\circ}, 43.2^{\circ}, 57.1^{\circ}$ and $62.9^{\circ}$ respectively. These peaks can be indexed as or were associated with (220), (311), (400), (511) and (440) planes of pure iron oxide $/ \mathrm{Fe}_{3} \mathrm{O}_{4}$. The obtained peaks were

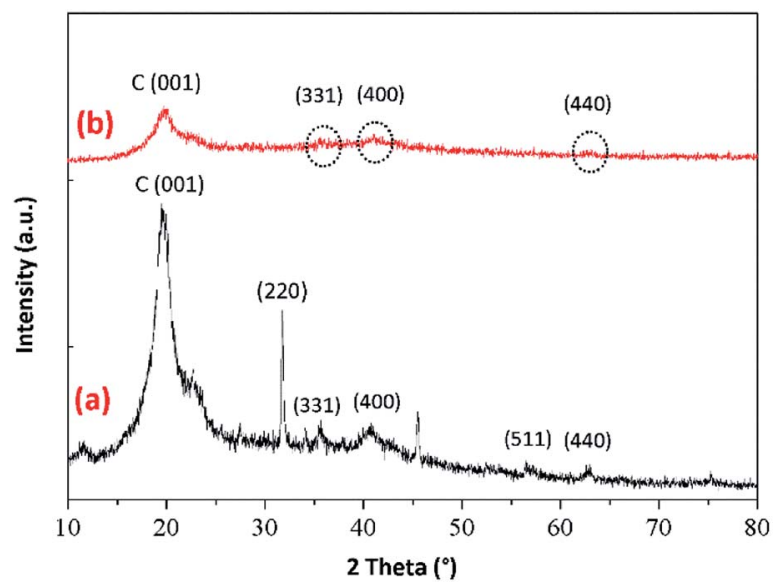

Fig. 4 Powder X-ray diffraction patterns of (a) PVA-SA-PMNPs and (b) the prepared bio-magnetic membrane capsules (BMMCs) after reaction with primary and secondary cross-linking agents (displaying the amorphous carbon and magnetite structures). (Reproduced from Ali et al. ${ }^{24}$ Copyright@2019, with permission from Elsevier Ltd.) very close to the published reports, as described in JCPDS card no. $19-0629 .^{21,25-27}$ The peaks at $2 \theta=30^{\circ}, 35^{\circ}$ and $62.9^{\circ}$ mainly indicate the existence of $\mathrm{Fe}_{3} \mathrm{O}_{4}$ /PMNPs. ${ }^{3}$ The average diameter/ crystallite size measurements of the PMNPs were also carried out by using the Debye-Scherrer equation and it was estimated to be about $35-40 \mathrm{~nm}$, as previously reported by Ali et al. $^{3}$ Moreover, a typical broad reflection peak at around $2 \theta=20^{\circ}$ appeared, which can be assigned to the $\mathrm{C}(001)$ reflection of amorphous carbons that might be composed of irregular shapes. $^{21}$ The existence of the C (001) reflection mainly indicated the presence of $\mathrm{C}-\mathrm{OH}$ containing functional groups $(-\mathrm{OH}$, $-\mathrm{COOH},-\mathrm{C}-\mathrm{H})$, which were mainly associated with the mixture of PVA-SA-PMNPs in the sample, confirming the homogenous mixing of the PVA-SA mixture with the PMNP solution. ${ }^{25,26}$ In contrast, Fig. 4b suggested that the intensity of the peaks was significantly decreased during the fabrication process of the PVA-SA-PMNPs mixture with primary and secondary crosslinking agents, indicating the successful cross-linking of primary and secondary agents with the PVA-SA-PMNPs mixture. The intensity of the characteristic peak at around $2 \theta=$ $20^{\circ}$ was significantly decreased, indicating the consumption of $\mathrm{C}-\mathrm{OH}$ containing functional groups during the fabrication process. ${ }^{21}$ In addition, the strong characteristic peaks of iron oxide at around $2 \theta=35^{\circ}, 43.2^{\circ}$ and $62.9^{\circ}$ also appeared, indicating the presence of PMNPs in the fabricated BMMCs, despite the fact that the intensity of these peaks was lower compared to Fig. $4 \mathrm{a}^{3}{ }^{3}$ This might be due to the amalgamation of primary and secondary cross-linking agents with the PVA-SA-PMNPs mixture. Overall, the XRD results confirmed the presence of PMNPs and the depletion of $\mathrm{C}-\mathrm{OH}$ containing functional groups in the fabrication process of BMMCs.

3.2.3. Morphology of BMMCs/SEM analysis. The average diameter of the majority of the PMNPs was in the range of 35- 
$55 \mathrm{~nm}$ and they showed a granular homogenous spherical shape, the structure of $\mathrm{Fe}_{3} \mathrm{O}_{4}$ (magnetite), as previously reported by same research group. ${ }^{3}$ The particles were agglomerated due to the presence of $-\mathrm{OH}$ from the plant leaf extract. The surfaces of the PMNPs were coated with organic matter, playing an important role in restraining their aggregation and enhancing their dispersion and colloidal stability. ${ }^{3}$ SEM analysis was carried out to understand the morphology of the prepared BMMCs and to verify encapsulation. Fig. 5 illustrates the morphological changes in the freeze-dried BMMCs from the surface layer to the inner core. The prepared BMMCs possessed a top-heavy, macro-void and micro-porous type "3D honeycomb" like architecture. Some cracks or small fractures were also noted on the surface, along with the presence of pores of different diameters. Overall, the prepared BMMCs showed a micro-porous capsule 'shell' and a macro-porous core structure. Pores with diameters ranging from 8 to $45 \mu \mathrm{m}$ were developed in the core due to the presence of a high water content ( $\sim 90 \%)$, suggesting that PVA-SA retained a comparatively large surface area and porous configuration (Fig. 5a-d). The thickness of the capsule shell was $52 \pm 8.5 \mu \mathrm{m}$ and the pores in the cross-section of the capsule shell were around $3 \pm$ $0.5 \mu \mathrm{m}$ (Fig. 5d). The SEM results strongly suggested that the morphology of the prepared BMMCs was effected by the development of chemical bonds and can be considered as a 'fish egg' of spherical shell-nuclei being formed as a casting solution drop is injected into the primary cross-linking agent solution $\left(\mathrm{CaCl}_{2}+\mathrm{H}_{3} \mathrm{BO}_{3}\right)$. Initially, a compact, dense and micro-porous egg box membrane structure was formed due to the consumption of $-\mathrm{COO}^{-} / \mathrm{OH}^{-}$by the interaction with $\mathrm{Ca}^{2+}$ and $\mathrm{B}^{3+}$. As the outer surface formed, a gradient developed between the primary cross-linking agent solution and the PVA-SA mixture to develop an inner core (Fig. $5 \mathrm{~d}$ ). The thickness of the capsule "shells" was prolonged inward with the passage of time but prevented the leakage of solution from the capsule inner core, which may be responsible for decreasing the chance and speed of a smooth interaction between polymer and reagents, that led to the improvement in the pore size. In addition, GA played an important role in modifying the BMMC morphology by creating a looser and macro-porous structure in the inner surface/core, to further enhance the density of pores (Fig. 5e). The pore sizes remarkably decreased after incorporating GA because it retained an excellent 'healing' potency due to the presence of $-\mathrm{OH}$, by maintaining a smooth interaction between polymer and reagents (Fig. 5e). Moreover, the PMNPs were agglomerated into micro-sized packs by the strong hydrogen bonding, and these were well dispersed in the PVA-SA mixture, resulting in notably enhanced mechanical properties (Fig. 5e and j). Furthermore, the porous macro-structure remarkably improved the surface area in the core, and this eased the movement of pollutants (toxic dyes and metal ions) within the core network by creating a pore channel. This will also enhance the adsorptive capability of the capsule adsorbent by generating more vacant/active sites for the adsorbate.

3.2.4. XPS analysis. The XPS spectrum was also obtained to recognize the elemental contents and surface composition of the prepared BMMCs (Fig. 6). The XPS results proposed two major peaks at 284.6 and $532.25 \mathrm{eV}$, associating to $\mathrm{C} 1 \mathrm{~s}$ and $\mathrm{O}$

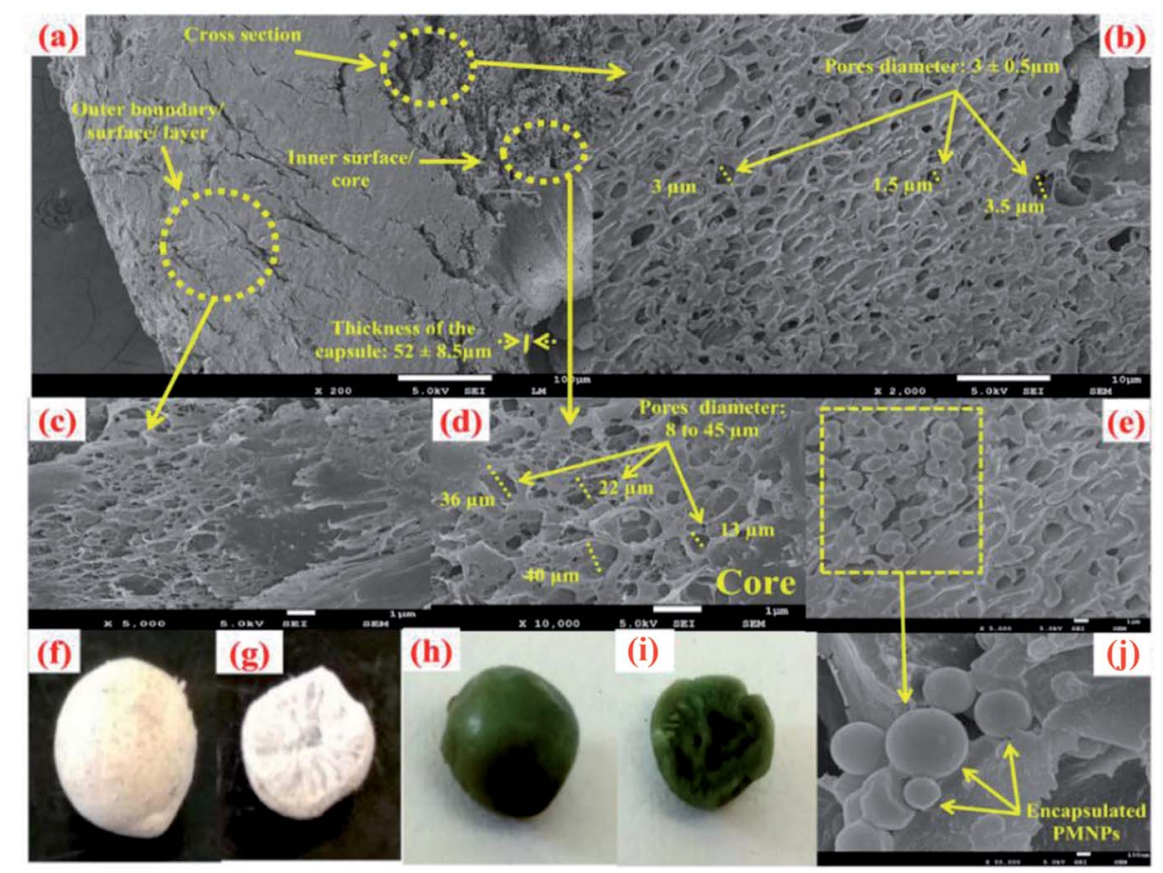

Fig. 5 Scanning electron microscopy (SEM) images of (a) the fabricated bio-magnetic membrane capsules (BMMCs), (b) cross-sectional area of the BMMCs, (c) outer boundary/surface/layer of the BMMCs, (d, e $\& \mathrm{j}$ ) inner surface/core of the BMMCs, (f) real pictorial view of the outer boundary/surface/layer of the BMMCs, (g) real pictorial view of the cross-sectional area of the BMMCs, (h) real pictorial view of the outer boundary/surface/layer of the BMMCs after the sorption of cationic MG dye, and (i) real pictorial view of the cross-sectional area of the BMMCs (after the sorption of cationic MG dye). (Reproduced from Ali et al. ${ }^{24}$ Copyright@2019, with permission from Elsevier Ltd.) 

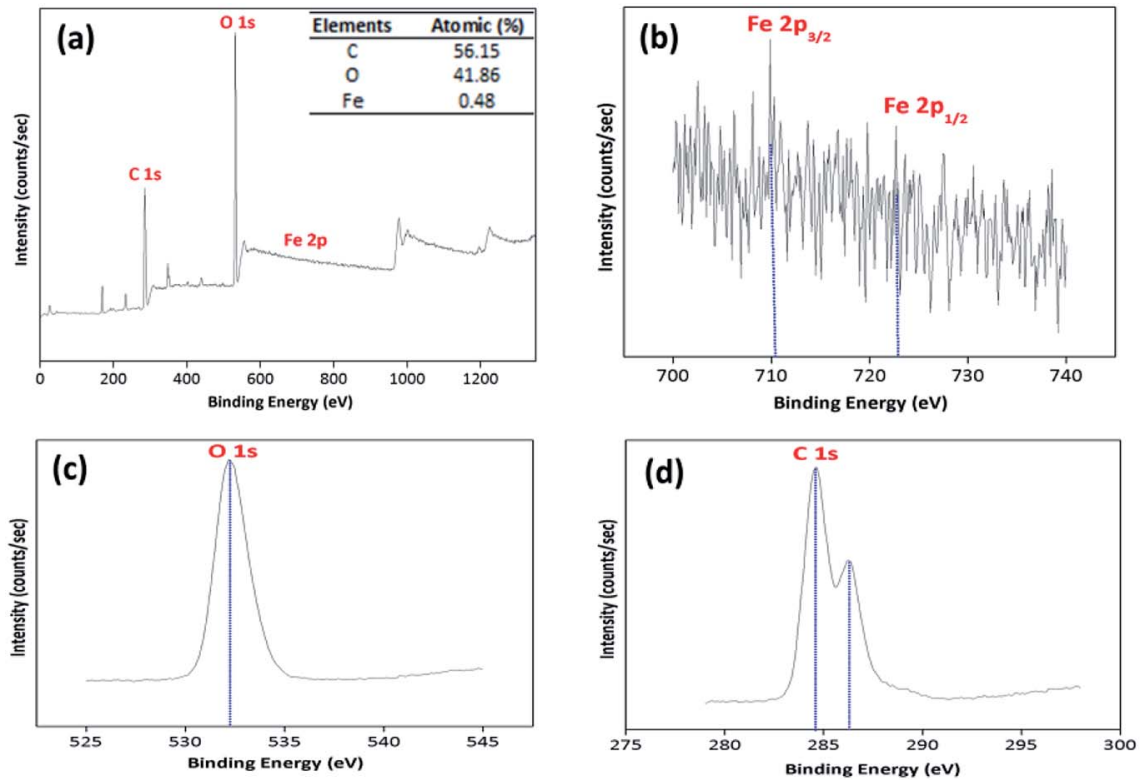

Fig. 6 X-ray photoelectron spectrum (XPS) of (a) bio-magnetic membrane capsules (inset table shows the atomic percentages of the elements); (b) high resolution XPS spectrum of Fe 2p; (c) high resolution XPS spectrum of $O 1 \mathrm{~s}$; (d) high resolution XPS spectrum of $C$ 1s.

1s, respectively (Fig. 6a). In addition, a small peak at $709.9 \mathrm{eV}$ for Fe 2p, indicating the existence/encapsulation/loading of PMNPs on/in the BMMCs (Fig. 6b). High resolution XPS spectra of $\mathrm{O} 1 \mathrm{~s}$ showed only one major peak at around $532.8 \mathrm{eV}$, which can be assigned to hydrophilic functional groups ( $-\mathrm{OH}$ and $\mathrm{O}-\mathrm{C}-\mathrm{O})$ (Fig. 6c). Similarly, the high resolution spectra of $\mathrm{C}$ 1s depicted two peaks at 284.6 and $287.8 \mathrm{eV}$ in the bending energy range of 275-305 eV (Fig. 6d). These attributes illustrated the availability of two $\mathrm{C}$ atoms with different chemical natures, as expected. The major peak at around $284.6 \mathrm{eV}$ in $\mathrm{C} 1 \mathrm{~s}$ can be allocated to $\mathrm{C}-$ $\mathrm{C} / \mathrm{C}=\mathrm{C}$ bands, which might be linked to the hydrophilic functional groups present in/on the surface of PVA, SA, GA and PMNPs.

Moreover, the high resolution XPS spectra of Fe 2p were also studied to investigate the structure of $\mathrm{Fe}_{3} \mathrm{O}_{4}$. As expected, two small peaks at 710.6 and $724.7 \mathrm{eV}$ emerged in the binding range of 700-740 eV, which were related to $\mathrm{Fe} 2 \mathrm{p}_{3 / 2}$ and $\mathrm{Fe} 2 \mathrm{p}_{1 / 2}$ respectively, confirming the presence of $\mathrm{PMNPs} / \mathrm{Fe}_{3} \mathrm{O}_{4}$. The peak at $\mathrm{Fe} 2 \mathrm{p}_{3 / 2}$ is typically associated with $\mathrm{Fe}$ in $\mathrm{Fe}_{3} \mathrm{O}_{4} / \mathrm{PMNPS}$ (Fig. 6b). The peak intensities were low, because a small amount of PMNPs was incorporated during the fabrication of BMMCs. The XPS results described that the atomic percentages of $\mathrm{C}, \mathrm{O}$ and Fe were $56.15,41.86$ and $0.48 \%$, respectively. Importantly, the XPS results were well matched with the EDX results and confirmed the loading/encapsulation of PMNPs.

3.2.5. EDX analysis. EDX was carried out to identify the chemical composition of and the presence of PMNPs in the prepared BMMCs (Fig. 7). According to the EDX analysis, the cross-sectional analysis of the prepared BMMCs was composed of the elements of carbon (C), oxygen (O), sodium (Na), sulfur $(\mathrm{S})$, chlorine $(\mathrm{Cl})$, potassium $(\mathrm{K})$, calcium $(\mathrm{Ca})$ and iron $(\mathrm{Fe})$. The EDX profile contained intense peaks of $\mathrm{C}$ and $\mathrm{O}$ in addition to $\mathrm{Na}, \mathrm{S}, \mathrm{Cl}, \mathrm{K}, \mathrm{Ca}$ and Fe (Fig. 7).
The $\mathrm{C}$ and $\mathrm{O}$ peaks in the EDX profile were associated with $-\mathrm{OH}$ and $\mathrm{COOH}$ groups, mainly linked to the PVA, SA, GA and PMNPs solution. On the other hand, the presence of Fe peaks in the EDX spectrum confirmed the encapsulation of PMNPs in the prepared BMMCs (Fig. 7). The peaks of $\mathrm{Ca}$ and $\mathrm{Cl}$ can be related to the primary cross-linking agent, i.e. $\mathrm{CaCl}_{2}$. While the intense peak of $\mathrm{Na}$ was mainly linked to SA. In addition, the presence of $\mathrm{K}$ and $\mathrm{S}$ peaks can be assigned to the plant biomolecules, present in the plant leaf extract. The results indicated that the atomic percentages as obtained by EDX quantification were C $(61.21 \%), \mathrm{O}(35.08 \%), \mathrm{Na}(0.72 \%), \mathrm{S}(0.43 \%), \mathrm{Cl}$ $(1.17 \%), \mathrm{K}(0.20 \%), \mathrm{Ca}(0.78 \%)$ and $\mathrm{Fe}(0.40 \%)$ (Fig. 7$)$. The presence of $\mathrm{Fe}$ homogenously distributed throughout the sample directed the smooth loading of PMNPs in the PVA-SA mixture, though in a small amount $(1.56 \%)$. For the fabrication of BMMCs, $4: 1(\mathrm{v} / \mathrm{v})=$ [PVA (10.0 wt\%) : SA-PMNPs (3.0 wt \%)] $=20.0 \mathrm{~g}$ PVA : $5.0 \mathrm{~g}$ SA-PMNPs solution was employed. Thus,

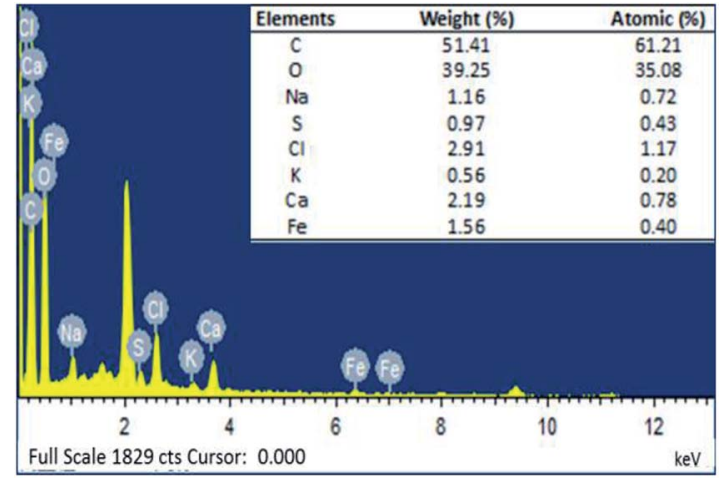

Fig. 7 Energy dispersive X-ray (EDX) image of the prepared biomagnetic membrane capsules (BMMCs). (Reproduced from Ali et al. ${ }^{24}$ Copyright@2019, with permission from Elsevier Ltd.) 
based on the EDX quantification, the total amount of $\mathrm{C}, \mathrm{O}$ and $\mathrm{Na}$ was $91.88 \%$, excluding the amounts of $\mathrm{S}, \mathrm{Cl}, \mathrm{K}$ and $\mathrm{Ca}$. Whereas, the amount of Fe element was $1.56 \%$ and this reading was very close to our theoretical calculation: i.e. $0.430 \mathrm{~g}$ (2 wt $\%$ PMNPs in $4: 1(\mathrm{v} / \mathrm{v})=$ PVA-[SA-PMNPs]). Moreover, despite having a very low Fe content $(1.56 \%)$ of the PMNPs, the prepared BMMCs had a very high saturation magnetization $\left(11.02 \mathrm{emu}^{-1}\right)$. Notably, the said value was approximately 2.5 times lower than the saturation magnetization value obtained for PMNPs (50.95 emu $\mathrm{g}^{-1}$ ). This means that a slight loading of PMNPs into capsules is enough to produce significantly high $M_{\mathrm{s}}$, which makes the capsules suitable for easy magnetic separation from an aqueous environment. Overall, the EDX results ensured the presence of $\mathrm{C}, \mathrm{O}, \mathrm{Na}, \mathrm{Cl}, \mathrm{Ca}$ and $\mathrm{Fe}$ in the fabrication of BMMCs (Fig. 7).

3.2.6. Thermogravimetric analysis (TGA). The TGA plot of the prepared BMMCs indicated three major mass loss steps in the tested temperature range of $0-800{ }^{\circ} \mathrm{C}$ (Fig. 8). The first weight loss $(18 \%)$ appeared in the temperature range of $34-$ $250{ }^{\circ} \mathrm{C}$, indicating the removal of $\mathrm{H}_{2} \mathrm{O}$ /moisture or residual solvent, physisorbed, and chemisorbed $\mathrm{H}_{2} \mathrm{O}$ molecules in the sample. ${ }^{3}$ The second major weight loss $(40 \%)$ occurred at $250-$ $370{ }^{\circ} \mathrm{C}$, suggesting the elimination or pyrolysis or decomposition or loss of hydrophilic functional groups of the PVA-SA. ${ }^{28}$ Finally, the third weight loss (26\%) occurred in the temperature range of $370-560{ }^{\circ} \mathrm{C}$, indicating the decomposition/ combustion of the polymer structure and/or disintegration of the PMNP structure. ${ }^{29}$ Further, there no weight loss was noticed above $560{ }^{\circ} \mathrm{C}$ and BMMCs exhibiting a $16 \%$ weight residue remained. The TGA results suggested that the weight percentages of moisture, PVA-SA and PMNPs were 18, 40 and $26 \%$, respectively. Importantly, these results also clearly indicated that the fabricated BMMCs were fully capped with $-\mathrm{OH}$, $-\mathrm{COOH},-\mathrm{C}-\mathrm{H}$, etc., mainly associated with PVA-SA-PMNPs, and they were responsible for decreasing the capsules' overall thermal stability as well as increasing their adsorptive capability. ${ }^{7,30}$

3.2.7. Magnetic measurements. The hysteresis loop of the freeze-dried BMMCs was obtained using VSM at a temperature of $300 \mathrm{~K}$ by a pertaining magnetic field from -15 to $+15 \mathrm{kOe}$

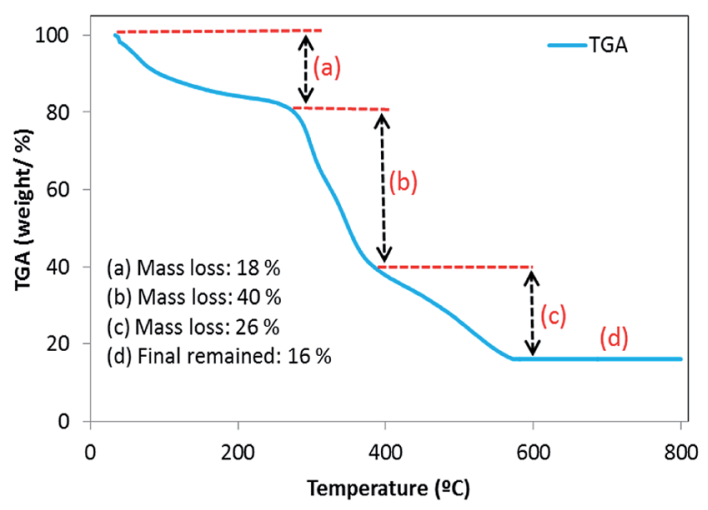

Fig. 8 Thermogravimetric analysis (TGA) plot of the fabricated biomagnetic membrane capsules (BMMCs). (Reproduced from Ali et al. ${ }^{24}$ Copyright@2019, with permission from Elsevier Ltd.)

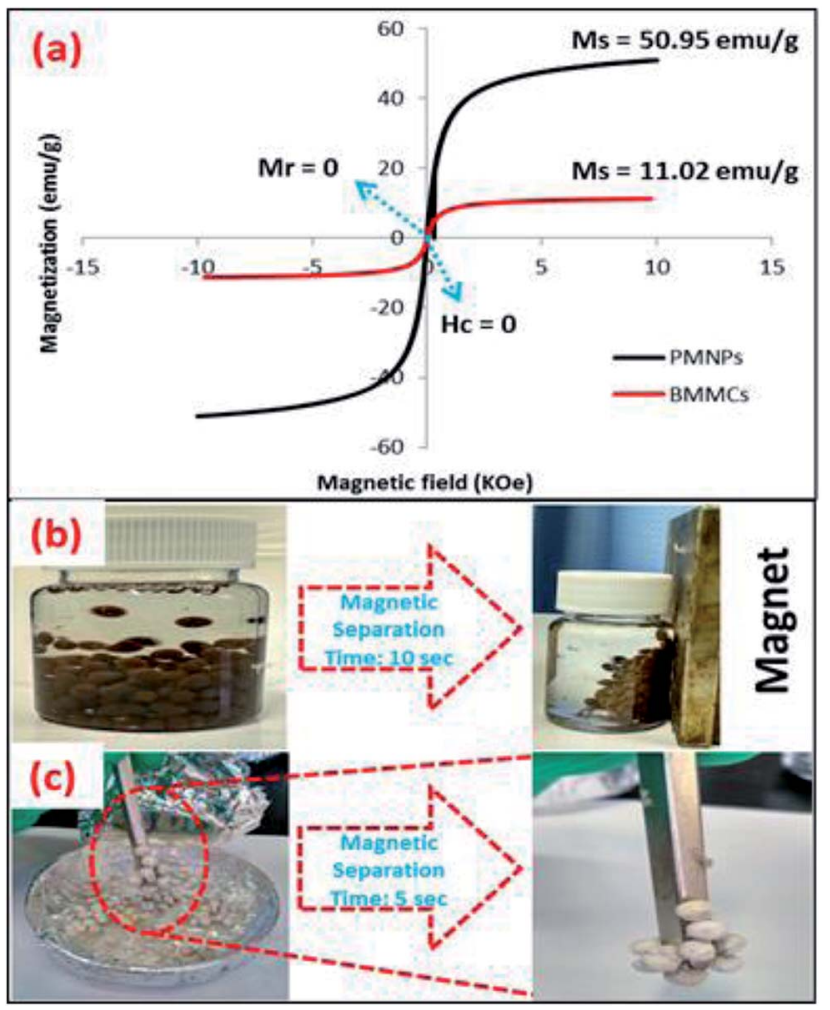

Fig. 9 (a) $\mathrm{M}-\mathrm{H}$ hysteresis loop/vibrating sample magnetometer (VSM) measurement of the prepared PMNPs and bio-magnetic membrane capsules (BMMCs) at a temperature of $300 \mathrm{~K}$; and magnetic separation studies of the prepared BMMCs in (b) an aqueous environment, and (c) freeze-dried conditions using a simple hand-held magnet. (Reproduced from Ali et al. ${ }^{24}$ Copyright@2019, with permission from Elsevier Ltd.)

(Fig. 9a), and compared with the hysteresis loop of bare PMNPs. The saturation magnetization $\left(M_{\mathrm{s}}\right)$ value at a temperature of $300 \mathrm{~K}$ was discovered to be $11.02 \mathrm{emu} \mathrm{g}^{-1}$, which is enough to be useful for repeated magnetic separation. Despite this fact, the obtained value was approximately 2.5 times lower than the $M_{\mathrm{S}}$ of PMNPs (50.95 emu $\mathrm{g}^{-1}$ ). The values of remanence magnetization $\left(M_{\mathrm{s}}\right)$ and coercivity $\left(H_{\mathrm{c}}\right)$ were zero, indicating that the prepared BMMCs retained superparamagnetic behavior. Importantly, the superparamagnetic nature of PMNPs was not damaged due to the encapsulation/loading of PMNPs into the PVA and SA mixture during the fabrication of BMMCs. However, the value of $M_{\mathrm{s}}$ was affected. Moreover, despite having a very low Fe content $(1.56 \%)$ of the PMNPs, the prepared BMMCs had a very high saturation magnetization (11.02 emu $\mathrm{g}^{-1}$ ). This means that a slight loading of PMNPs into the capsules is enough to produce a significantly high $M_{\mathrm{S}}$ value, which not only makes the capsules suitable for easy magnetic separation from an aqueous environment, but also demonstrates their superior chemical stability against acid attack in contrast to naked PMNPs, that faced oxidation of the particles, resulting in decreases in the stability of PMNPs for long-term applications. The prepared BMMCs showed the comparatively highest saturation magnetization value and magnetic separation time over most of the other documented composite materials, highly prerequisite for improving the 
Table 4 Comparison of bio-magnetic membrane capsules (BMMCs) with some other reported magnetic composite sorbents in terms of magnetic separation time and saturation magnetization $\left(M_{\mathrm{s}}\right)$

Magnetic sorbent

Magnetic separation

time (s)

$M_{\mathrm{s}}\left(\mathrm{emu} \mathrm{g}^{-1}\right)$

Reference

PVA-SA-embedded $\mathrm{Fe}_{3} \mathrm{O}_{4}$ magnetic nanoparticles (MNPs)

$\mathrm{Fe}_{3} \mathrm{O}_{4} @$ @mesoC

$\mathrm{Fe}_{3} \mathrm{O}_{4} @ \mathrm{SiO}_{2} @ \mathrm{CS}-\mathrm{TETA}-\mathrm{GO}$

Bio-magnetic membrane capsules (BMMCs)

-

$-$

-

10

FeCo/GC NCs@MSNs

$\mathrm{Fe}_{3} \mathrm{O}_{4} @(\mathrm{PAH} / \mathrm{GO}-\mathrm{COOH})_{2}$ nanocomposites

CMC-g-CMPVA film loaded with $\mathrm{Fe}_{3} \mathrm{O}_{4} / \mathrm{SiO}_{2}$ nanoparticles

-

-

11.02

$-\quad 17.1$

- 21.5

5

5.5

8.22

36.87

7

26

27

Present study

28

25

31

Reproduced from Ali et al. ${ }^{24}$ Copyright@2019, with permission from Elsevier Ltd.

water/wastewater treatment process and maintaining the economic feasibility of a treatment system (Table 4). In addition, the fabricated BMMCs can easily be reused for consecutive treatment cycles and they can easily be separated from effluents within $5-10 \mathrm{~s}$ by using a simple hand-held magnet, due to their superparamagnetic behavior, without generating secondary pollutants (Fig. 9b and c).

\subsection{Influence of different operating parameters on the adsorptive performance and properties of BMMCs for the removal of cationic toxic malachite green (MG) dye}

3.3.1. Effect of various amounts of PMNP encapsulation into membrane capsules. First, the influence of the amount of PMNP encapsulation was investigated for optimizing the amount of PMNP encapsulation and improving the interaction of pollutants with the active sites of the BMMCs. The amount of PMNPs was varied from 1 to $5 \mathrm{wt} \%$ by keeping the PVA-SA ratio constant and different types of bio-magnetic capsules were fabricated. A fixed amount of $0.02 \mathrm{~g}$ of BMMCs of each type was mixed into $40 \mathrm{~mL}$ of MG dye solution $\left(25 \mathrm{mg} \mathrm{L}^{-1}\right)$ for $24 \mathrm{~h}$ at $\mathrm{pH} 6.5$. The results indicated that the removal efficiency of MG dye was increased from 50 to $92.23 \%$ by increasing the amount of PMNP encapsulation from 1 to $4 \mathrm{wt} \%$, and then suddenly decreased from 92.23 to $57.89 \%$ by a further loading of PMNPs (Fig. 10a). A possible explanation of this trend is that at low loading of PMNPs, the prepared BMMCs had enough vacant/active sites for accommodating MG molecules, but as the loading of PMNPs increased, the vacant/active sites were occupied by the PMNPs via hydrogen bonding, and meanwhile the empty pores were filled, which
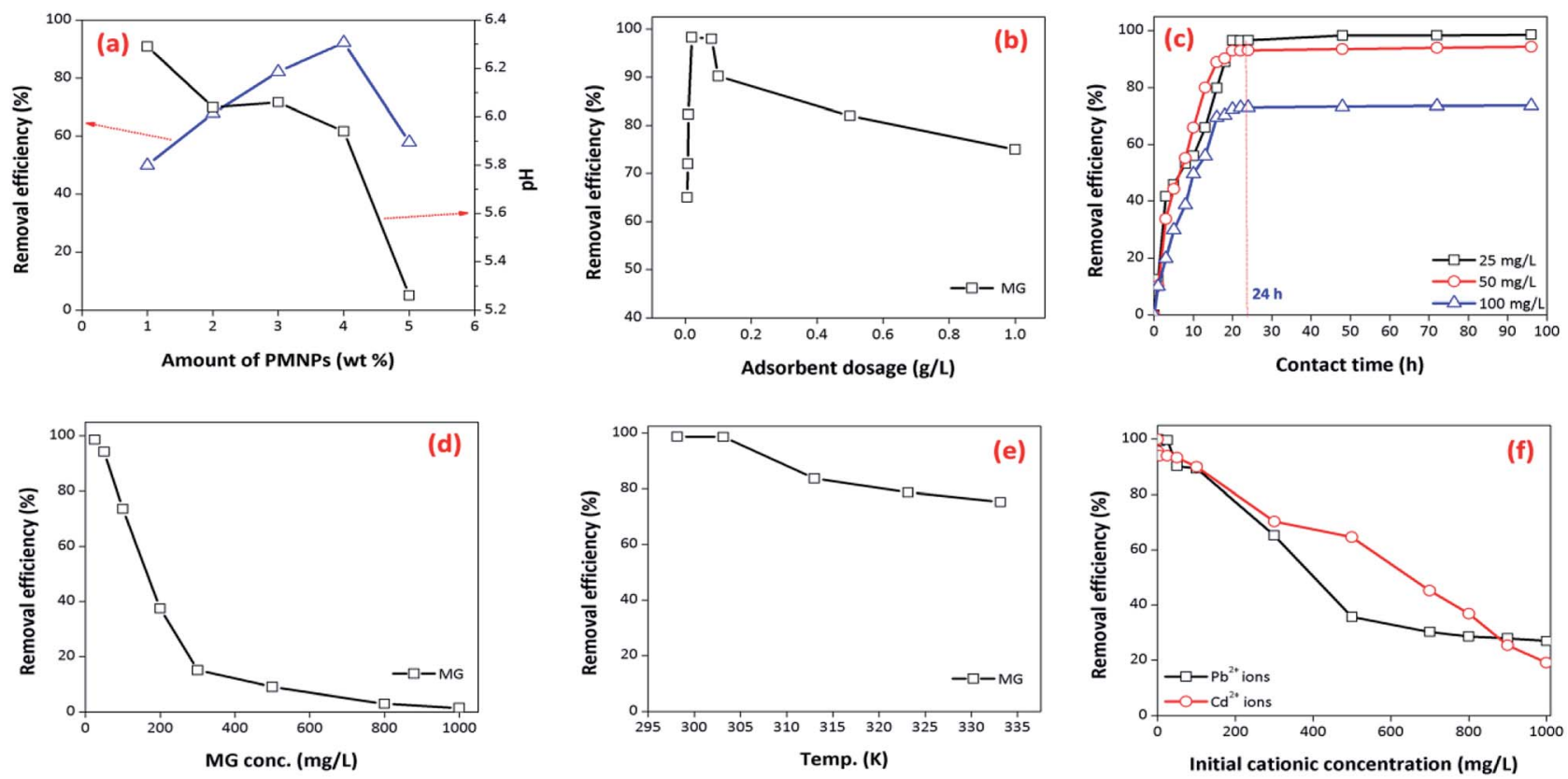

Fig. 10 (a) Effect of various amounts of PMNP encapsulated into BMMCs on the removal efficiency of cationic MG dye, (b) effect of adsorbent/ BMMCs dosage on the removal the efficiency of cationic MG dye by BMMCs (dosages $=0.0062-1 \mathrm{~g} \mathrm{~L}^{-1} ; \mathrm{C}_{\mathrm{O}}=25 \mathrm{mg} \mathrm{L}^{-1}$; contact time $=24 \mathrm{~h}$; replication $=3$; standard deviation: \pm 1.23 ); (c) effect of contact time on the removal efficiency of $M G$ dye by $B M M C s$ (dosage $=0.02 \mathrm{~g} \mathrm{~L}^{-1}$; replication $=3$; standard deviation: \pm 1.42 ); (d) effect of initial concentration of MG dye (replication $=3$; standard deviation: \pm 1.69 ); (e) effect of reaction temperature (dosage $=0.02 \mathrm{~g} \mathrm{~L}^{-1}$; replication $=3$; standard deviation: \pm 2.03 ); and (f) effect of co-existing cationic pollutants on the removal efficiency of $M G$ dye by BMMCs (dosage $=0.02 \mathrm{~g} \mathrm{~L}^{-1}$; replication $=3$; standard deviation: \pm 1.03 ). 
created a hindrance to the smooth penetration of MG molecules into the inner pores/core of the capsule. On the other hand, the $\mathrm{pH}$ of the solution was also reduced from 6.29 to 5.26, suggesting that the active sites released enough $\mathrm{H}^{+}$to create repulsion as well as competition between/among MG molecules and $\mathrm{H}^{+}$to fill/capture vacant sites. Hence, the findings of the present study depicted that a small amount of PMNP encapsulation is enough to utilize the maximum active sites of the BMMCs that will also minimize the fabrication cost.

3.3.2. Effect of BMMCs/adsorbent dosages. Further, the dosages of the prepared BMMCs were also optimized to keep the treatment process more economical and efficient. For this purpose, the dosages of the BMMCs $\left(0.0062\right.$ to $\left.1 \mathrm{~g} \mathrm{~L}^{-1}\right)$ were added into $40 \mathrm{~mL}$ of MG dye solution $\left(25 \mathrm{mg} \mathrm{L}^{-1}\right)$ for $24 \mathrm{~h}$ at $\mathrm{pH}$ 6.5. These findings showed that the removal efficiency of MG was initially increased progressively from 65 to $98.29 \%$ by increasing the dosage from 0.0062 to $0.02 \mathrm{~g} \mathrm{~L}^{-1}$, and then later it was reduced from 98 to $60 \%$ by further increasing the dosage from 0.08 to $1 \mathrm{~g} \mathrm{~L}^{-1}$ (Fig. 10b). As expected, the increase in the removal performance might be due the increase in the availability of the active sites on/inside the capsules, but at high dosages, the capsules had enough active sites that released $\mathrm{H}^{+}$, which created repulsion and as well as competition between/ among MG molecules and $\mathrm{H}^{+}$, consequently reducing removal efficiency. Overall, a plateau was established in the range of 0.02 to $0.08 \mathrm{~g} \mathrm{~L}^{-1}$, suggesting an equilibrium between MG molecules and adsorbents. This phenomenon might be showing that capsules had an ion-exchange behavior in the removal of $\mathrm{MG}$ dye. Therefore, a dose of $0.02 \mathrm{~g} \mathrm{~L}^{-1}$ of BMMCs was chosen for further experiments.

3.3.3. Effect of contact time. The influence of contact time was also investigated at $\mathrm{pH} 6.5$ and different initial concentrations of MG dye (25-100 $\mathrm{mg} \mathrm{L}^{-1}$ ) using a $0.02 \mathrm{~g} \mathrm{~L}^{-1}$ adsorbent dosage (Fig. 10c). These findings illustrated that removal of MG dye occurred in two phases. In the first phase, a fast removal of MG dye was noted within a contact time of $15 \mathrm{~h}$, and then a second phase started, where a slower removal was observed in the time range of 15-48 h. After this, it approached a plateau. The equilibrium time was different for different concentrations of MG dye (25-100 $\mathrm{mg} \mathrm{L}^{-1}$ ). Overall, the optimum equilibrium time was $24 \mathrm{~h}$ for the maximum removal of $\mathrm{MG}$ dye at all three concentrations i.e. 25, 50 and $100 \mathrm{mg} \mathrm{L}^{-1}$ (Fig. 10c). A fast removal of MG dye occurred at the beginning due to the presence of more vacant/active sites on the exterior surface of the bio-magnetic capsules. As the external surface occupied/totally cross-linked with cationic MG ions, then MG molecules faced hindrance to penetrating into the inner parts/core of the membrane capsule, and this made it difficult to fill the remaining vacant/active sites owing to the presence of electrostatic repulsion between the adsorbates in solution and those sorbed onto the surface of the membrane capsules. However, with the passage of time, MG molecules entered/diffused via micro-pores to macro-pores, and interacted with the remaining active/vacant sites. Consequently, the removal of MG dye approached equilibrium after $24 \mathrm{~h}$. Later, no significant removal was noted up to the contact time of $96 \mathrm{~h}$, and the color of the BMMCs had completely changed from chocolate to green owing to the sorption of MG dye (Fig. 10c).

3.3.4. Effect of initial MG dye concentration and temperature. To investigate the influence of initial MG dye concentration on the removal efficiency of the prepared BMMCs, the concentration of MG dye was varied from 25 to $1000 \mathrm{mg} \mathrm{L}^{-1}$ using a capsule dosage of $0.02 \mathrm{~g} \mathrm{~L}^{-1}$ at $\mathrm{pH} 6.5$ (Fig. 10d). The results indicated that the removal efficiency of $\mathrm{MG}$ dye decreased from 98.61 to $1.5 \%$ by increasing the initial MG dye concentration from 25 to $1000 \mathrm{mg} \mathrm{L}^{-1}$. This is a common phenomenon because the amount of adsorbate was greater than the available active sites, as the initial concentration of MG dye increased (Fig. 10d). This indicated that the available active sites on the membrane capsules were the limiting factor for dye sorption. Overall, more than $80 \%$ of MG dye removal efficiency was achieved in the concentration range of $25-100 \mathrm{mg} \mathrm{L}^{-1}$; later it was drastically decreased due to the non-availability of the vacant sites on/in the membrane capsules. This means that a higher dosage was needed to keep a high MG removal efficiency at a higher concentration of MG dye (Fig. 10d). Further, the effect of temperature on the removal efficiency of MG dye was also observed in the range of temperature 298.15-333.15 K at an initial MG dye concentration of $25 \mathrm{mg} \mathrm{L}^{-1}$ using $0.02 \mathrm{~g} \mathrm{~L}^{-1}$ dosage (Fig. 10e). The removal efficiency of MG dye reduced (from 98.75 to $75.23 \%$ ) as the temperature increased from 298.15 to $33.15 \mathrm{~K}$. Whereas the adsorptive capacity was not influenced significantly, suggesting that the removal of MG dye was spontaneous and exothermic in nature. Furthermore, this might indicate that the degree of randomness/freedom increased at the solid-liquid interface during the removal/ sorption process.

3.3.5. Adsorption competition/effect of co-present constituents. In order to assess adsorption competition, two binary systems $\left(\mathrm{Pb}^{2+}+\mathrm{MG}\right.$ dye and $\mathrm{Cd}^{2+}+\mathrm{MG}$ dye $)$ were designed and applied (Fig. 10f). The findings showed that the co-existence of cationic ions did have a significant influence on the adsorptive removal of MG dye by BMMCs under all the tested concentrations. It was observed that the co-presence of $\mathrm{Cd}^{2+}$ in solution created higher competition than $\mathrm{Pb}^{2+}$, and the removal efficiency of $\mathrm{MG}$ dye decreased to $19 \%$ with the increase in concentration of $\mathrm{Cd}^{2+}$ from 1 to $1000 \mathrm{mg} \mathrm{L}^{-1}$ within $24 \mathrm{~h}$. This might be due to the fact that hydrophilic functional groups $(-\mathrm{OH}$ and $-\mathrm{COOH})$ attached on/in the membrane capsules had a strong affinity for capturing $\mathrm{Pb}^{2+}$ and $\mathrm{Cd}^{2+}$ from solution instead of cationic MG, and developed an inner sphere complex by the reaction with metal ions due to the presence of the small hydrated radii of both metal ions, as reported previously. ${ }^{3}$ Further, MG dye is a basic cationic dye and its selectivity may be hampered in the presence of soft acid (metal ions). On the other hand, BMMCs had $\sim 90 \%$ water content and high ionic strength would make the hydrogel shrink and become more compact, which could also reduce the dye removal efficiency. Overall, the results revealed that MG removal efficiency was hampered by an increase in metal ion concentration in solution. However, initially at a lower concentration of metal ions $\left(1-100 \mathrm{mg} \mathrm{L}^{-1}\right)$, the removal efficiency of $\mathrm{MG}$ dye was more than $80 \%$, indicating that the membrane capsules had enough vacant/active sites to 
compensate for both cationic MG molecules and metal ions, but as the concentration of metal ions increased in solution, sorption selectivity developed to occupy these vacant sites, inhibiting MG removal efficiency. Hence, pre-knowledge of the coexisting cationic ions (hydrated radii, electro-static charge, and size) is compulsory to optimize operational prerequisites for the smooth implementation of membrane capsule technology in the water/wastewater treatment process.

3.3.6. Effect of solution $\mathbf{p H}$. The $\mathrm{pH}$ of the solution is often influenced by both the aqueous chemistry and functional groups of the adsorbents. For this purpose, the removal performance of MG dye was investigated by varying the $\mathrm{pH}$ from 2 to 12 (Fig. 11). Presently, the influence of solution $\mathrm{pH}$ on the removal efficiency of MG dye by PMNPs, PVA-SA capsules and the prepared MBBCs were considered. Initially, the point of zero charge $\left(\mathrm{pH}_{\mathrm{PZC}}\right)$ for all three adsorbents was calculated by the $\mathrm{pH}$ drift method (Fig. 11a), according to Ali et al. ${ }^{3}$ (Text-SIII $\dagger$ ). The findings showed that initially the removal efficiency increased from 2.43 to $97.56 \%$ in the $\mathrm{pH}$ range $2-6$, and then it was almost stable and increased to $99.39 \%$ in the $\mathrm{pH}$ range 6-12 (Fig. 11b). The interaction of MG cationic dye on/in the prepared BMMCs depended mainly on the surface charge and active sites on/in the capsules. A possible explanation of this trend was that the prepared BMMCs had hydrophilic functional groups. At low $\mathrm{pH}$ (2-4), the hydrophilic functional groups on in the membrane capsules were neutralized and/or interacted with protons $\left(\mathrm{H}^{+}\right)$ and protonated MG molecules, and consequently repulsive forces restricted the smooth interaction of MG molecules with
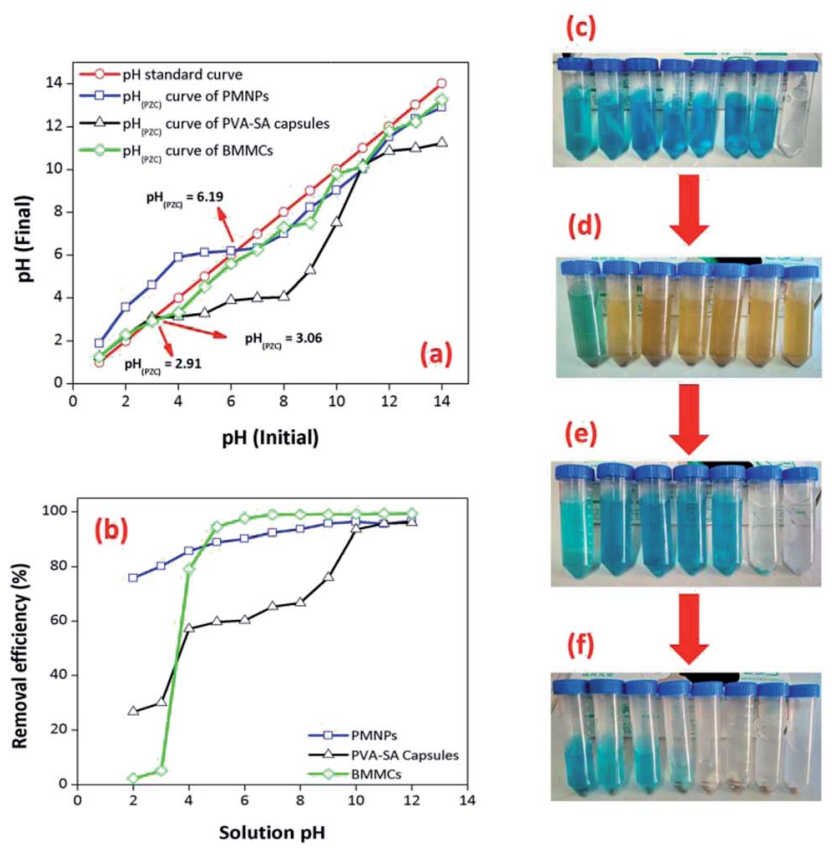

Fig. 11 (a) Point of zero charge ( $\mathrm{pH}_{\mathrm{PZC}}$ ) of PMNPs, PVA-SA-capsules and BMMCs; (b) Effect of solution $\mathrm{pH}$ on the removal efficiency of malachite green (MG) by PMNPs, PVA-SA-capsules and BMMCs. Interval of $\mathrm{pH}(2-12)$; initial dye concentration: $25 \mathrm{mg} \mathrm{L}^{-1}$; dosage: $0.02 \mathrm{~g} \mathrm{~L}^{-1}$; solution volume: $40 \mathrm{~mL}$; temperature: $25^{\circ} \mathrm{C}$ and agitation time: 120 min; replication $=3$; standard deviation: \pm 2.29 [figures show the real conditions of the (c) solution after reaction with (d) PMNPs, (e) PVA-SA-capsules and (f) BMMCs]. the active sites of the adsorbent. However, at higher $\mathrm{pH}$, the prepared BMMCs had lots of negatively charged sites, exposed for binding with positively charged pollutants (MG), and consequently improved the removal efficiency. This behavior might be addressed in this way: the $\mathrm{pH}_{\mathrm{PZC}}$ of the prepared BMMCs was 2.91, and as expected, the surface of the adsorbents was negatively charged at $\mathrm{pH}>\mathrm{pH}_{\mathrm{PZC}}$, which permitted the sorption of cationic MG ions on/in the membrane capsules. Thus, for better performance, the $\mathrm{pH}$ of the MG solution was kept stable at 6.5 for the other experiments. Similarly, the influence of solution $\mathrm{pH}$ on the removal of MG dye was also observed for PVA-SA membrane capsules. The findings showed that a more or less similar trend was found as for BMMCs, but the removal efficiency of MG dye by PVA-SA membrane capsules was reasonably less than for BMMCs in the $\mathrm{pH}$ range 4-9. In comparison, the removal efficiency of MG dye by BMMCs was $97.65 \%$ at $\mathrm{pH} 6.5$, while it was $65.29 \%$ by PVA-SA membrane capsules (Fig. 11b). However, the removal efficiency of MG dye by PVA-SA membrane capsules was significantly improved up to 95.99\% in the $\mathrm{pH}$ range 9-12. A possible explanation for this difference might be that the membrane capsules loaded with PMNPs had more negatively charged sites than un-loaded PVASA membrane capsules because the PMNPs had their own functional groups (-OH or $-\mathrm{COOH})$ on the surface of the PMNPs that led to enhanced free energy/vacant/active sites for the sorption of more MG molecules; consequently, they had 1.4 times higher removal efficiency than PVA-SA membrane capsules and a reduced $\mathrm{pH}_{\mathrm{PZC}}$ for better performance even in low $\mathrm{pH}$ ranges. On the other hand, the bare/naked/un-loaded PMNPs were also employed in removing MG dye to better address the utilization of the prepared BMMCs (Fig. 11b). In addition, the light absorption results of MG dye before and after the reaction with prepared bio-magnetic capsules at different $\mathrm{pH}$ are also shown in Fig. SII, $\uparrow$ indicating that MG dye was mainly sorbed on/in the BMMCs. For a better understanding, the real condition of the MG solution after reaction with PMNPs, PVA-SA membrane capsules and BMMCs is also shown in Fig. 11c-f.

\subsection{Adsorption kinetics studies}

Most often, adsorption kinetics are employed to estimate the adsorption performance and application of lab-scale adsorbents. In order to evaluate the kinetics of MG dye sorption on/in the BMMCs, the influence of contact time was noted using an adsorbent dosage of $0.02 \mathrm{~g} \mathrm{~L}^{-1}$ in the MG dye concentration range of $25-100 \mathrm{mg} \mathrm{L}^{-1}$ at $\mathrm{pH} 6.5$ (Fig. 12). It can be seen that initially a fast sorption occurred within a contact time of $20 \mathrm{~h}$, and approached stability during the time period of 20 to $96 \mathrm{~h}$ (Fig. 12a). This fast sorption can be assigned to the availability of greater hydrophilic functional groups/negatively charged sites on/in the membrane capsules, which facilitated the rapid interaction of MG ions with negatively charged vacant/active sites, as previously examined by FTIR, EDX and XPS analyses. Overall, the fast sorption rate was achieved within a contact time of $20 \mathrm{~h}$, while after $24 \mathrm{~h}$ adsorptive equilibrium was accomplished. 

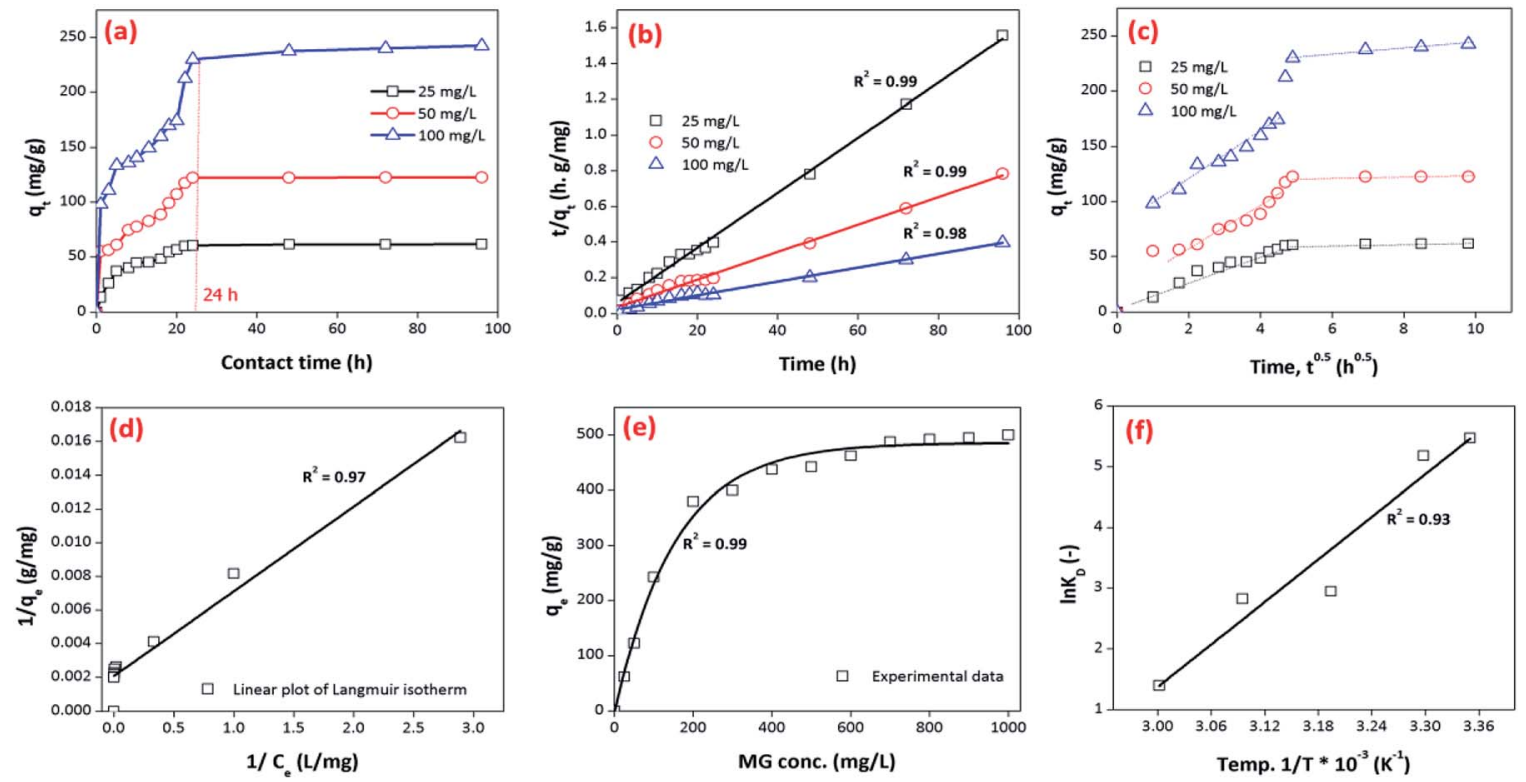

Fig. 12 (a) Kinetics of malachite green (MG) dye sorption by bio-magnetic membrane capsules (BMMCs) (dosage $=0.02 \mathrm{~g} \mathrm{~L}^{-1}$; replication $=3$; standard deviation: \pm 2.83 ); (b) the linear plot of the pseudo-second-order model of $M G$ dye sorption by $B M M C s$ (dosage $=0.02 \mathrm{~g} \mathrm{~L}^{-1}$; replication $=3$; standard deviation: \pm 2.83 ); (c) intra-particle diffusion kinetic model fit for malachite green (MG) dye sorption by BMMCs (dosage $=0.02 \mathrm{~g} \mathrm{~L}^{-1}$; replication $=3$; standard deviation: \pm 2.83 ); (d) the linear plot of the Langmuir isotherm model for malachite green (MG) dye

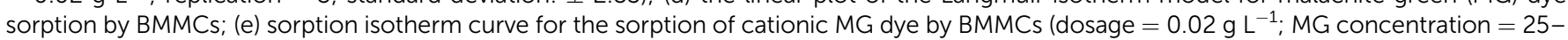
$1000 \mathrm{mg} \mathrm{L}^{-1}$; replication $=3$; standard deviation: \pm 3.09); and (f) thermodynamic plot for the sorption of malachite green (MG) dye by BMMCs (dosage $=0.02 \mathrm{~g} \mathrm{~L}^{-1}, C_{\mathrm{o}}=25 \mathrm{mg} \mathrm{L}^{-1}$; replication $=3$; standard deviation: \pm 1.49 ).

To further explore the adsorption mechanism and to determine the kinetic parameters of MG dye sorption on/in the membrane capsules, various frequently used adsorption kinetics models were utilized. It is supposed that different independent processes may be concerned in controlling sorption kinetics during the adsorptive removal of pollutants that can be performed in series or parallel. For instance: (i) chemisorption/chemical reaction, (ii) bulk transport, (iii) intra-particle diffusion and (iv) film diffusion/external mass transfer. For this purpose, kinetic models including pseudofirst-order, pseudo-second-order, Elovich, intraparticle diffusion/Weber and Morris, and liquid film diffusion were

Table 5 Kinetic parameters for the sorption of cationic malachite green (MG) dye by bio-magnetic membrane capsules (BMMCs) [replication = 3; standard deviation: \pm 2.83$]^{a}$

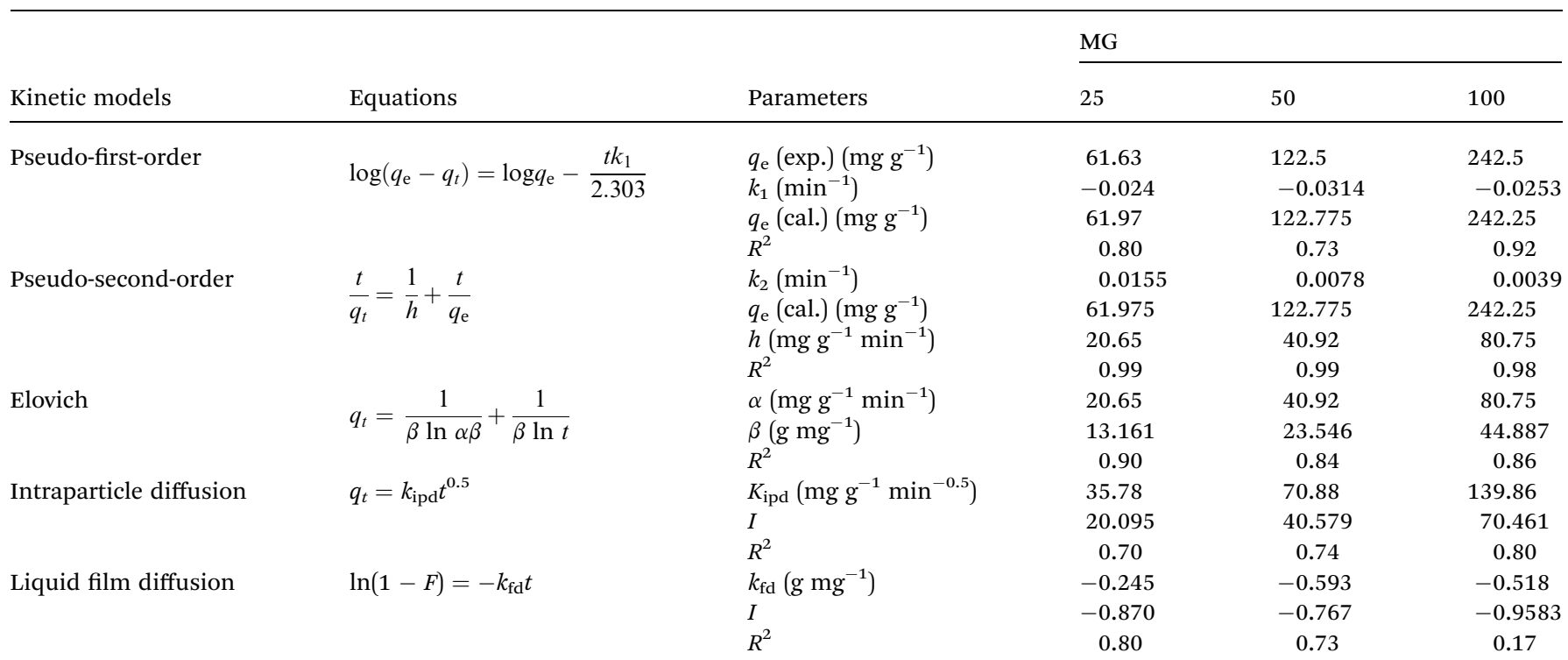

${ }^{a}$ Given in ESI (Text-SIV). 
employed to fit the experimental data. The obtained results are presented in Table 5.

In all these experiments, the regression coefficient values $\left(R^{2}\right)$ for the second-order kinetic model were estimated to be greater than 0.97, which were higher than other employed kinetics models, indicating the presence of ion-exchange and/or chemisorption/chemical reaction mechanism (Fig. 12b). In addition, the calculated $q_{\mathrm{e}} /$ adsorptive capacities by the secondorder kinetic model were $61.975 \mathrm{mg} \mathrm{g}^{-1}$ at $25 \mathrm{mg} \mathrm{L}^{-1}$, $122.775 \mathrm{mg} \mathrm{g}^{-1}$ at $50 \mathrm{mg} \mathrm{L}^{-1}$ and $242.25 \mathrm{mg} \mathrm{g}^{-1}$ at $100 \mathrm{mg} \mathrm{L}^{-1}$, which were very close to the experimental $q_{\mathrm{e}}$ /adsorptive capacities $\left(61.63 \mathrm{mg} \mathrm{g}^{-1}\right.$ at $25 \mathrm{mg} \mathrm{L}^{-1}, 122.5 \mathrm{mg} \mathrm{g}^{-1}$ at $50 \mathrm{mg} \mathrm{L}^{-1}$ and $242.5 \mathrm{mg} \mathrm{g}^{-1}$ at $100 \mathrm{mg} \mathrm{L}^{-1}$ ), suggesting that sorption of MG dye on/in the BMMCs, was dominated by chemisorption and/or ionexchange mechanisms. Furthermore, the values of $k_{2}$ were less than $h$, suggesting a rapid adsorption of MG dye initially and subsequently slower sorption. Adsorption and desorption were also discovered by using Elovich's kinetic model. The values of $\alpha$ were greater than $\beta$, suggesting that the BMMCs had a greater adsorption rate than desorption. The $R^{2}$ values of this model were less than 0.90 , indicating the non-applicability of this model.

It is often reported that dye sorption is normally regulated by either the liquid phase mass transport rate or through the intraparticle mass transport rate. In order to investigate this phenomenon, the Weber and Morris kinetic equation was employed. Normally, this model is used to investigate the following adsorption processes that might be occurring: (i) bulk diffusion, (ii) film diffusion, (iii) intra-particle diffusion and (iv) chemical reaction via ion-exchange or the adsorption of pollutants at the vacant/active sites on the adsorbent surface. The plots/graph line did not pass through the origin, but data points can be explained in double lines by a difference in slope and intercept, suggesting that more than one process (boundary layer adsorption) might be implicated. For instance, the first straight line had a significant slope, suggesting that initially MG molecules covered/transported/interacted with the external surface/vacant sites of the BMMCs via film diffusion, and then these cationic MG ions entered into the solid phase or pores of the membrane capsules via intra-particle diffusion, which is shown in the second straight line. Furthermore, the values of $k_{\text {ipd }}$ and intercept ( $I$ ) also increased as the concentration of MG dye increased in the solution, suggesting the boundary layer diffusion effect occurred owing to the entry of MG molecules into the pores of the membrane capsules (Fig. 12c). Consequently, it can be declared that MG molecules sorbed on/in the membrane capsules owing to the presence of both surface adsorption and boundary layer adsorption or intra-particle diffusion. Finally, the liquid film diffusion mechanism was also used and its straight line did not pass through the origin, but showed proximity to the origin. This might be due to the rapid mixing of batch experiments, which can give rise to a discrepancy between the rate of mass transfer in the initial and final stages of the adsorption process. Overall, based on the adsorption kinetic results and fitting of the experimental data to the second-order kinetic model, it was demonstrated that the adsorption of MG dye on/in the BMMCs principally happened due to an ion-exchange and/or chemisorption mechanism. Moreover, double lines in the intra-particle diffusion kinetic model imply the presence of boundary layer diffusion, which might be due to the transportation of MG molecules into the inner core of the BMMCs via micro-pores to macropores, as formerly observed by SEM.

\subsection{Adsorption isotherm studies}

Adsorption isotherms were investigated to check the sorption performance of fabricated BMMCs as well as the interaction between the cationic MG and adsorbent/membrane capsule surface. The findings showed that sorption capacity increased as the initial concentration of MG dye increased, and then reached saturation at $C_{\mathrm{o}}=600 \mathrm{mg} \mathrm{L}{ }^{-1}$ (Fig. 12e). The saturation sorption capacities were calculated as $500 \mathrm{mg} \mathrm{g}^{-1}$ for MG dye. For estimating the sorption isotherm, frequently used equilibrium models (Langmuir isotherm, Freundlich isotherm, Temkin isotherm and Dubinin-Radushkevich isotherm) were utilized to discuss the MG dye interaction with BMMCs and the estimated values are listed in Table 6. The experimental data were fitted into the models and discussed according to the values of $R^{2}$ and the linearity of the isotherms. The findings indicated that the Langmuir isotherm represented a better $R^{2}(0.97)$ than the other isotherm models, intimating the monolayer adsorption of MG dye on/in the BMMCs (Fig. 12d). This means that the membrane capsule surfaces were homogeneous and that all the active sites had the same affinity for adsorbing MG molecules. In addition, the values of $K_{\mathrm{L}}$ for MG dye were in the range of $0.37-0.99$, suggesting that adsorption was favorable, because the favorability of the adsorption isotherm depends mainly on the $K_{\mathrm{L}}$ value. If $K_{\mathrm{L}}>1$, the adsorption isotherm is unfavorable; if $K_{\mathrm{L}}=1$, the adsorption isotherm is linear; if $K_{\mathrm{L}}=$ 0 , the adsorption isotherm is irreversible; and if $K_{\mathrm{L}}<1$, then the adsorption isotherm is favorable. The calculated maximum adsorption capacity by the Langmuir model was $500 \mathrm{mg} \mathrm{g}^{-1}$ using a BMMC dosage of $0.02 \mathrm{~g} \mathrm{~L}^{-1}$ at $\mathrm{pH}$ 6.5. Overall, the evidence from the isotherm and kinetic studies confirmed that cationic MG dye was removed by the interaction with oppositely charged functional groups attached on/in the BMMCs via ion-exchange and/or electrostatic attractions. Furthermore, the uniform/smooth distribution of $-\mathrm{OH}$ and $-\mathrm{COOH}$ groups on/in the BMMCs played an important role in improving the sorption capacity and removal efficiency of MG dye.

\subsection{Thermodynamic studies}

In order to evaluate the type of adsorption, thermodynamic parameters were also estimated (Table 7). The values of $\Delta G^{\circ}$ were negative for all temperatures, suggesting that sorption was thermodynamically feasible and spontaneous in nature (Fig. 12f). The value of $\Delta G^{\circ}$ decreased with the increase in temperature, indicating a lower feasibility of adsorption at higher temperature. From the negative value of enthalpy $\left(\Delta H^{\circ}\right)$ we inferred that sorption was exothermic in nature in the temperature range of 298.15-333.15 K. Further, the value of $\Delta H^{\circ}\left(39.387 \mathrm{~kJ} \mathrm{~mol}^{-1}\right)$ was greater than $20.9 \mathrm{~kJ} \mathrm{~mol}^{-1}$, suggesting that adsorption of MG dye on/in the BMMCs mainly happened due to an ion-exchange and/ or chemisorption mechanism, as formerly confirmed in the kinetic and isotherm studies. On the other hand, the positive value of entropy $\left(\Delta S^{\circ}\right)$ indicates an increase in randomness/ adsorbed species degree of freedom at the solid-solution 
Table 6 Isotherm constants for sorption of cationic MG dye by bio-magnetic membrane capsules (BMMCs) [replication = 3; standard deviation: $\pm 3.09]^{a}$

\begin{tabular}{|c|c|c|c|}
\hline Isotherm models & Equations & Parameters & Values \\
\hline Langmuir isotherm & $\begin{aligned} \frac{1}{q_{\mathrm{e}}} & =\frac{1}{K_{\mathrm{L}} q_{\max } C_{\mathrm{e}}}+\frac{1}{q_{\max }} \\
K_{\mathrm{L}} & =\frac{1}{1+b C_{\mathrm{e}}}\end{aligned}$ & $\begin{array}{l}q_{\max }\left(\mathrm{mg} \mathrm{g}^{-1}\right) \\
b\left(\mathrm{~L} \mathrm{mg}^{-1}\right) \\
K_{\mathrm{L}} \\
R^{2}\end{array}$ & $\begin{array}{l}500 \\
0.0021 \\
0.99-0.37 \\
0.97\end{array}$ \\
\hline Freundlich isotherm & $\log q_{\mathrm{e}}=\left(\frac{1}{n}\right) \log C_{\mathrm{e}}+\log k_{\mathrm{F}}$ & $\begin{array}{l}1 / n \\
k_{\mathrm{F}}\left(\mathrm{mg} \mathrm{L}^{-1}\right) \\
R^{2}\end{array}$ & $\begin{array}{l}0.4199 \\
1.5923 \\
0.49\end{array}$ \\
\hline
\end{tabular}

interface during the process of sorption. In addition, it was also noticed that the removal efficiency and sorption capacity decreased with the increase in temperature (Fig. SX†). This might be due to damage to the morphology/structure of the BMMCs, which reduced vacant sites on/in the membrane capsules and/or decreased the rate of pore diffusion. It is also confirmed by BET analysis that the swelling nature of the non-rigid porous structures is helping to desorb the pollutants/molecules instead of sorption due to the rupture in macro-porosity at higher temperature. Hence, a higher temperature is favorable to desorb pollutants from the membrane capsules or for desorption processes rather than sorption.

\subsection{Desorption and reusability studies}

Adsorbent stability, regeneration and reusability for consecutive treatment cycles are considered important traits to implement proposed adsorption technology, economically and feasibly technically for real applications. Hence, initially, regeneration experiments were planned to choose a suitable regeneration solution, and its optimum volume for the removal of MG dye by BMMCs (Fig. 13). For this purpose, first, a $0.02 \mathrm{~g} \mathrm{~L}^{-1}$ membrane capsule dose was added into $40 \mathrm{~mL}$ of $\mathrm{MG}$ dye solution $\left(25 \mathrm{mg} \mathrm{L}^{-1}\right)$ for sorption of MG molecules, and then after approaching equilibrium, these BMMCs were separated from solution, and added into different kinds of regeneration solution in order to achieve maximum replenishment using minimum cost and energy. The findings of these experiments are given in ESI (Fig. SIV-IX†). In short, basic $(\mathrm{NaOH})$, salty ( $\mathrm{NaCl})$, acidic ( $\mathrm{HCl}$ and EDTA), water/ $\mathrm{H}_{2} \mathrm{O}$ and organic solvent (methanol) solutions were employed to desorb MG molecules and to retrieve the membrane capsules. In the first phase, an acidic environment was selected, such as the $\mathrm{HCl}$ selected by many other researchers. The results indicated that desorption efficiency decreased from 35 to $10 \%$ as the concentration of $\mathrm{HCl}$ increased from 25 to $100 \%$.

Despite this fact, $\mathrm{HCl}$ had protons $\left(\mathrm{H}^{+}\right)$to exchange with adsorbed cationic MG ions (Fig. 13). However, interestingly, it was noticed that firstly the color of the bio-magnetic membrane capsules changed from brown/chocolate to white by increasing $\mathrm{HCl}$ concentration from 5 to $30 \%$ (Fig. SIII $†$ ). This might be due to the leaching of encapsulated PMNPs from the membrane, indicating that the prepared BMMCs could not survive in a more acidic environment. Thereafter, the membrane capsules disappeared from solution by further increasing the

Table 7 Thermodynamic parameter values for the sorption of MG dye by bio-magnetic membrane capsules at different temperatures (K) [replication $=3$; standard deviation: \pm 1.49$]^{a}$

\begin{tabular}{llll}
\hline Equations & Temperature (K) & $\Delta G^{\circ}\left(\mathrm{kJ} \mathrm{mol}^{-1}\right)$ & $\Delta H^{\circ}\left(\mathrm{kJ} \mathrm{mol}^{-1}\right)$ \\
\hline$\Delta G^{\circ}=-R T \ln K_{D}$ & 298.15 & -13563.56 & -39.387 \\
$\ln K_{\mathrm{D}}=\frac{\Delta S^{\circ}}{R}-\frac{\Delta H^{\circ}}{R T}$ & 303.15 & -13069.43 & \\
& 313 & -7669.33 & \\
& 323.15 & -7588.07 & \\
& 333.15 & -3865.72 &
\end{tabular}

${ }^{a}$ Given in ESI (Text-SIV). 


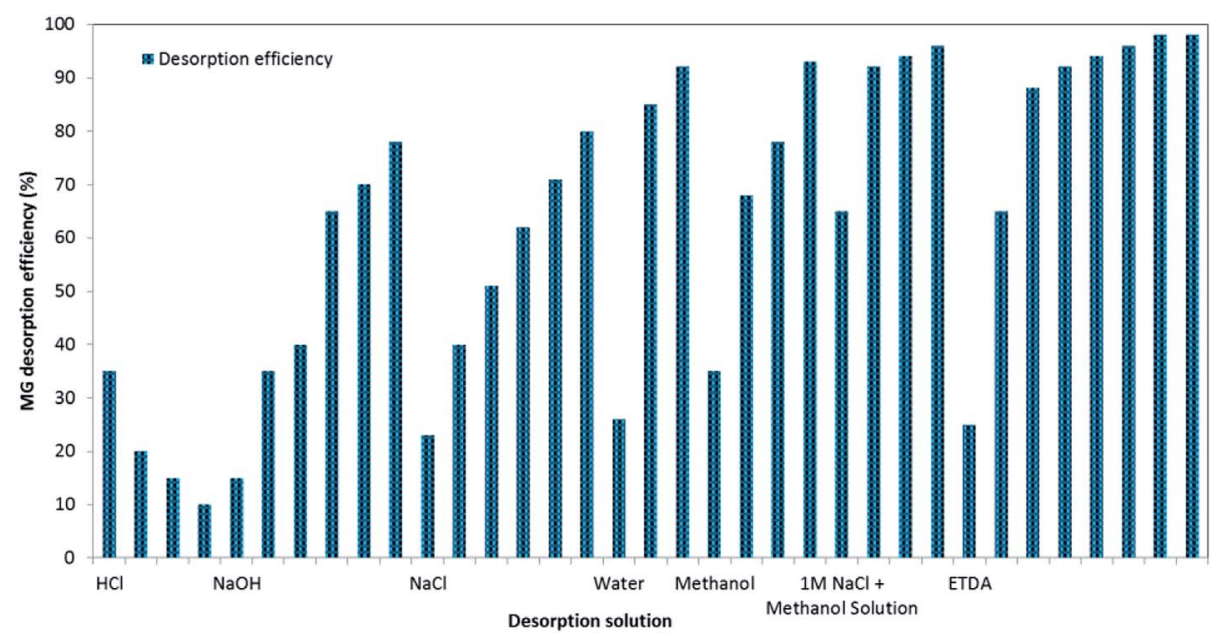

Fig. 13 Effect of different concentrations of desorption solutions on the desorption efficiency of malachite green (MG) dye (adsorbents dosage $=0.02 \mathrm{~g} \mathrm{~L}^{-1}, \mathrm{MG}$ initial concentration $\left(C_{0}\right)=25 \mathrm{mg} \mathrm{L}^{-1}$; replication $=3$; standard deviation: \pm 4.67 ).

concentration of $\mathrm{HCl}$ from 30 to $100 \%$, confirming the complete loss of stability and morphology at higher pH (Fig. SIII $\dagger$ ). In the second phase, in the basic conditions, it was noticed that the desorption efficiency was improved to $80 \%$ by increasing $\mathrm{NaCl}$ from 0.1 to $3 \mathrm{M}$. This might be due the replacement of $\mathrm{Na}^{+}$with cationic MG and/or the presence of a higher affinity of - $\mathrm{OH}$ and $-\mathrm{COOH}$, to replace cationic MG with $\mathrm{Na}^{+}$via an ion-exchange process (Fig. 13). However, complete regeneration was not achieved due to the occurrence of a 'salting-out effect', because the solubility of the dyes often deteriorated with increasing salt concentration in the aqueous environment. ${ }^{32}$ It is also suggested that some other forces (hydrophobic interactions) along with electrostatic interactions and ion-exchange might complicate the interactions between MG ions and membrane capsules. Hence, in the third phase, it was supposed that an organic solvent (methanol) could destroy these additional forces, but it seemed ineffective in desorbing $\mathrm{MG}$ ions completely from the membrane capsules, indicating the copresence of other forces (hydrogen bonding, ion-exchange, and strong bonding between cationic MG and hydrophilic functional groups) along with the hydrophobic interactions. More or less similar results were found using basic solution $(\mathrm{NaOH})$. In the next phase, a combination of organic solvent and salt was employed to disconnect these forces (Fig. 13), which indicated that a combination was good for desorbing up to $96 \%$ of MG ions from membrane capsules. However, complete desorption was not achieved due to the co-presence of other forces (hydrogen bonding, and $\pi-\pi$ interaction/stackinglike polar $-\pi$ interactions and aromatic-aromatic interactions $/ \pi$ stacking) along-with ion-exchange, electrostatic and hydrophobic interactions. At this stage, there were hints found by applying various types of regeneration solution that the adsorption of MG dye on/in the bio-magnetic membrane capsules might be due to the combination of five types of interactions: i.e., ion-exchange, electrostatic interaction, hydrogen bonding, hydrophobic interaction, $\pi-\pi$ interaction/ stacking-like polar- $\pi$ interactions and aromatic-aromatic interactions/ $\pi$ stacking. In addition, the prepared BMMCs have a 3D honeycomb like structure, which has an outer surface and inner/core area, where hydrophilic functional groups, active and negatively charged sites are disturbed randomly on/in the membrane capsules (Fig. 13).

Consequently, they are creating other interactions automatically like hydrogen bonding, hydrophobic interaction and $\pi-\pi$ interaction/stacking like polar- $\pi$ interactions and aromaticaromatic interactions $/ \pi$ stacking, that are developing a strong bonding between cationic MG and adsorbents/membrane capsules, which are making it difficult to desorb MG dye from adsorbents/membrane capsules. On the other hand, MG dye has $\mathrm{N}^{+}$at only one of its terminal ends along with two methyl groups. Whereas, there are three aromatic rings, and one of these is connected to a nitrogen atom with two methyl groups. This means that the positive charge is not uniformly distributed over the MG molecule. So, only one terminal end which has a cationic $\mathrm{N}^{+}$side contributed to electrostatic interactions, while for the rest of the sides, the organic portion assisted the hydrophobic interaction and benzene rings/aromatic rings aided the hydrogen bonding, and $\pi-\pi$ interaction/stacking-like polar- $\pi$ interactions and aromatic-aromatic interactions $/ \pi$ stacking.

In the next phase, by keeping in mind all these interactions, a strong regeneration solution such as EDTA was selected, as recommended by other researchers (Fig. 13). The findings showed that EDTA had an excellent desorption performance over all the other employed solutions and showed 98\% MG desorption efficiency with a $1.5 \mathrm{M}$ EDTA solution, while $92 \%$ was achieved by applying $0.5 \mathrm{M}$ EDTA, indicating that EDTA had excellent characteristics for disengaging all these interactions due to the presence of two amines and four $-\mathrm{COO}^{-}$, which can replace four cationic MG sorbed on/in the membrane capsule with four $-\mathrm{COO}^{-}$sides. Meanwhile, it was also observed that the structure of membrane capsule was significantly damaged because of chelation, which sequestered $\mathrm{Ca}^{2+}$ and metal complexes by bonding with ETDA (Fig. 13). In fact, this phenomenon has destroyed the morphology of the membrane 
capsules, despite offering the greatest desorption efficiency. Finally, from an economic point of view, water was selected to desorb cationic MG from BMMCs and interestingly, $>90 \%$ desorption efficiency was achieved by increasing the volume of water from 10 to $50 \mathrm{~mL}$, indicating that the prepared BMMCs had a strong affinity to replace $\mathrm{H}^{+}$from solution due to the hydrophilic functional groups $\left(-\mathrm{O}^{-} /-\mathrm{COO}^{-}\right)$via an ionexchange mechanism. ${ }^{3}$ Hence, water was selected as environmentally friendly and cost-effective regeneration solution to desorb cationic MG from BMMCs.

Further, the feed-to-regeneration ratio ( $\mathrm{v} / \mathrm{v})$ was also elevated to attain a more economical and feasible ratio of regeneration solution to adsorbent (Fig. 14). It was noticed that initially the desorption efficiency was almost constant from 1 to 2.7 , and then reduced gradually by further boosting the feed-toregeneration ratio from 2.7 to 8 . Based on the results, about $90 \%$ desorption efficiency was achieved at a 2.7 feed-toregeneration ratio. Hence, this ratio (2.7) was selected as an optimum feed-to regeneration ratio for further studies to keep the membrane capsule technology sustainable and feasible.

Finally, the sorption-desorption of MG dye was investigated for ten consecutive treatment cycles by keeping the optimum feed-to-regeneration ratio (2.7) using a dosage $0.02 \mathrm{~g} \mathrm{~L}^{-1}$ of membrane capsules (Fig. 15). The findings indicated that the prepared BMMCs maintained their performance for up to four consecutive treatment cycles with continuing removal efficiency > $80 \%$, and then gradually reduced to $29 \%$. Each time the membrane capsules were separated by a magnet and regenerated using $15 \mathrm{~mL}$ of fresh water. Since the desorption efficiency was not $100 \%$, it can be supposed that a segment of sorbed MG dye remained on/inside the membrane capsules owing to the presence of other forces (hydrogen bonding, hydrophobic interaction and $\pi-\pi$ interaction/stacking), which might be not collapsed by water. Moreover, during the first four treatment cycles, no leakage of PMNPs was discovered, suggesting the smooth encapsulation of PMNPs into the membrane capsules via strong hydrogen bonding. On the other hand, after four cycles, the reusability reduced, which might be due to the demolition of the membrane capsule structure due to the dissolution of PMNPs or lack of the availability of active sites on/in the membrane capsule,

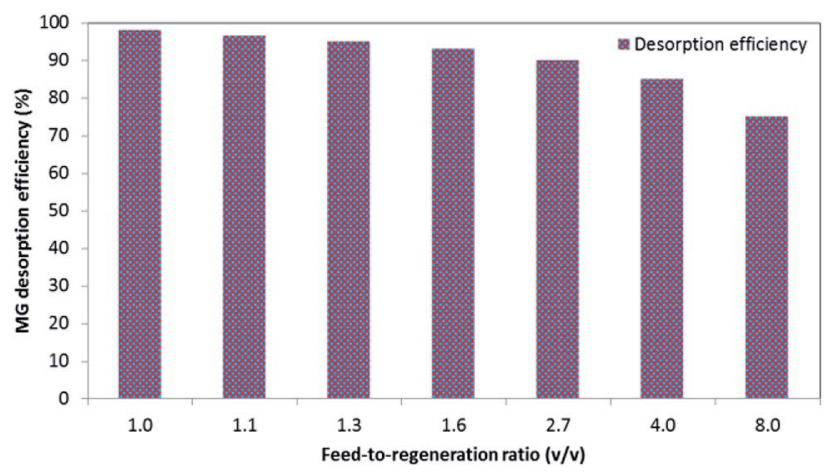

Fig. 14 Effect of different feed-to-regeneration ratios $(v / v)$ on the desorption efficiency of malachite green (MG) dye (water as regeneration solution; adsorbent dosage $=0.02 \mathrm{~g} \mathrm{~L}^{-1}, \mathrm{MG}$ initial concentration $\left(C_{\circ}\right)=25 \mathrm{mg} \mathrm{L}^{-1}$; replication $=3$; standard deviation: \pm 1.59 ).

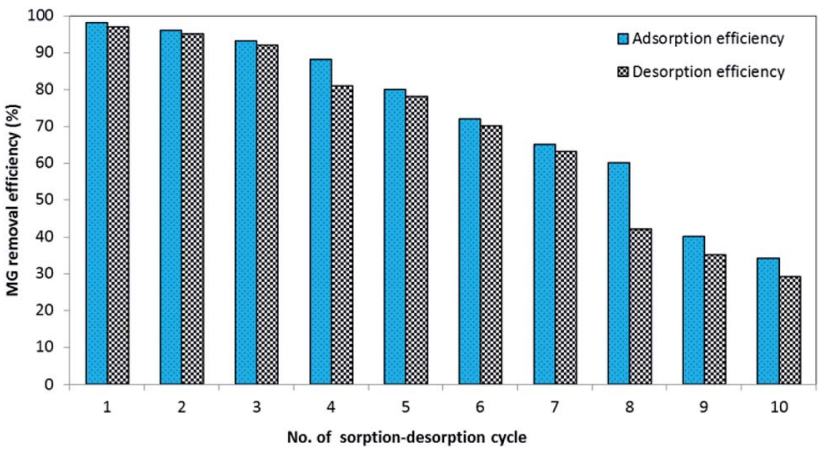

Fig. 15 Study of the stability and reusability of BMMCs for consecutive sorption-desorption cycles of malachite green (MG) dye $(15 \mathrm{~mL}$ of water as regeneration solution; adsorbent dosage $=0.02 \mathrm{~g} \mathrm{~L}^{-1}$, MG initial concentration $\left(C_{\mathrm{o}}\right)=25 \mathrm{mg} \mathrm{L}^{-1}$; replication $=3$; standard deviation: \pm 3.18 ).

because a segment of the sorbed MG dye remained on/inside the membrane capsule due to the presence of micro or macro pores/ voids. Similarly, Yue et al. ${ }^{16}$ prepared novel cellulose nanofiberreinforced sodium alginate-polyvinyl alcohol hydrogels for the removal of cationic MB dye from textile wastewater and reported that the developed adsorbent could be regenerated by using fresh water and it maintained sorption-desorption efficiency up to four consecutive treatment cycles. However, in our case, the reusability potential of the prepared adsorbent can be enhanced by changing the regeneration solution. As Fig. 13 depicts, the prepared adsorbent showed maximum regeneration potential, when EDTA solution was employed, while, from the economic point of view, in the present study, fresh water was used to regenerate prepared capsules to make the treatment process cheap and affordable to developing countries. Research on the changes in morphology and structure of the prepared BMMCs is underway and will be discussed in the next report. Overall, the fabricated BMMCs can be re-used for up to four consecutive treatment cycles by keeping the removal efficiency above $80 \%$. According to the mass balance approach, on average, an amount of $100 \mathrm{~mL}$ of treated water can be obtained from $160 \mathrm{~mL}$ of textile wastewater that contains cationic pollutants/MG dye just by using a dosage of $0.02 \mathrm{~g} \mathrm{~L}^{-1}$ adsorbent/membrane capsules.

\subsection{Adsorption mechanism/proposed removal mechanism}

The findings from the isotherm, kinetics, thermodynamic, regeneration and reusability examinations were further confirmed by utilizing FTIR and EDX analyses to investigate the probable adsorption mechanism of cationic MG toxic dye by BMMCs. The FTIR spectrum was obtained after the sorption of MG dye and compared with the spectrum of BMMCs (Fig. 16). The results showed that the stretching vibrations of hydroxyl $/-\mathrm{O}^{-}$functional groups (at around $3600-3300 \mathrm{~cm}^{-1}$ ) and carboxyl/ $-\mathrm{COO}^{-}$(at around 1500-1300 $\mathrm{cm}^{-1}$ ) were affected and extended inward, suggesting the sorption of cationic MG on/in the BMMCs via electrostatic interaction and/or an ion-exchange mechanism ([Dye]-2R-HN ${ }^{+}-{ }^{-} \mathrm{O}$ and [Dye]-2R-HN ${ }^{+}-{ }^{-} \mathrm{OOC}$ ). Furthermore, the stretching vibrations of $\mathrm{C}-\mathrm{H}\left(-\mathrm{CH}_{3} /-\mathrm{CH}_{2}\right)$ at around 3191$2898 \mathrm{~cm}^{-1}$ were also affected, suggesting the sorption of cationic MG on/in the BMMCs. This might also be due to the co-presence of 


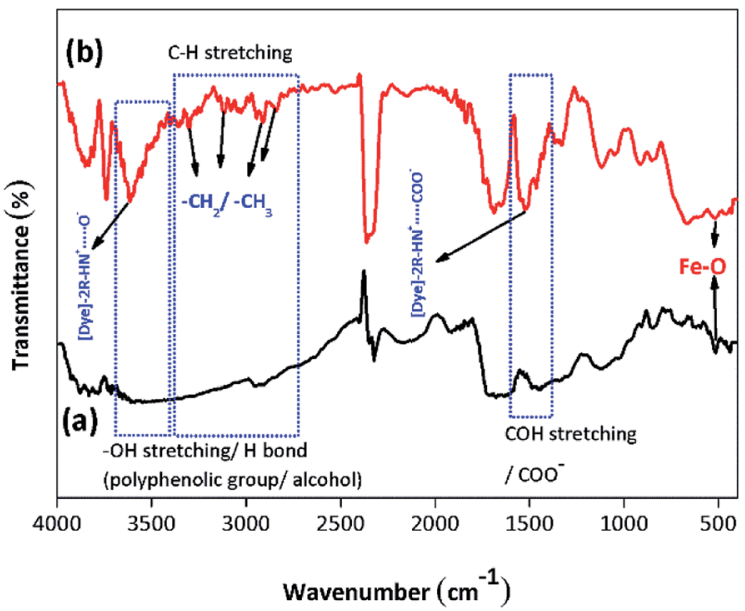

Fig. 16 Fourier transform infrared (FTIR) spectrum of bio-magnetic membrane capsules (BMMCs) (a) before and (b) after the sorption of cationic malachite green (MG) dye.

other interactions: i.e. hydrophobic interactions (between $\mathrm{CH}_{3}$ and $\mathrm{CH}_{3}$ groups attached on the MG molecules), hydrogen bonding (between the nitrogen atom attached on the MG molecules and -OH functional groups attached on in the membrane capsule) and $\pi-\pi$ interaction/stacking, e.g. polar- $\pi$ interactions (between benzene rings attached on the MG molecules and - $\mathrm{OH}$ functional groups attached on/in the membrane capsule) and aromaticaromatic interactions $/ \pi$ stacking (among benzene rings attached on the MG molecules). In addition, an absorption peak at $489 \mathrm{~cm}^{-1}$ (for $\mathrm{Fe}-\mathrm{O}$ ) did not have an influence, suggesting good stability/ smooth encapsulation/presence of PMNPs on/in the BMMCs (Fig. 16a and b). Overall, the FTIR results indicated the adsorption of cationic MG molecules via the attachment of cationic MG ions via $-\mathrm{O}^{-}$and $-\mathrm{COO}^{-}$functional groups on/in the BMMCs.
Therefore, based on the evidence obtained from isotherm, kinetics, thermodynamic, regeneration, reusability, FTIR and EDX studies along with the fact that MG dye and hydrophilic functional groups attached on/in the BMMCs are oppositely charged, indicated that electrostatic interactions/ion-exchange might be the leading adsorptive mechanism of cationic MG dye removal by BMMCs. In addition, the prepared BMMCs had a 3D honeycomblike structure, which had outer surface and inner core areas, where hydrophilic functional groups, vacant, active, and negatively charged sites were disturbed randomly on/inside the membrane capsules (Fig. 17). Therefore, the attachment of MG molecules was also disturbed randomly. Consequently, they created other interactions automatically, to develop a strong bonding between cationic MG and adsorbent/membrane capsule (Fig. 17). For example, initially cationic MG molecules interacted with the external surface/vacant sites via film diffusion, and then the rest of the cationic MG ions were transported/entered into or inside the solid phase or cores via intra-particle diffusion by creating a flow network owing to the presence of a micro-porous shell to macroporous core structure/channel, and meantime interacted with vacant sites through electrostatic interactions, hydrogen bonding, hydrophobic interaction and $\pi-\pi$ interaction/stacking-like polar$\pi$ interactions and aromatic-aromatic interactions/ $\pi$ stacking. For instance, in aqueous solution the MG dye molecule ionized as:

$$
[\text { Dye }]-2 \mathrm{R}-\mathrm{HNCl} \rightarrow\left[\text { Dye }-2 \mathrm{R}-\mathrm{HN}^{+}+\mathrm{Cl}^{-}\right.
$$

where $\mathrm{R}=\mathrm{CH}_{3}$.

These protonated or ionized MG molecules then interacted with negatively charged hydrophilic functional groups of BMMCs via an electrostatic interaction/ion-exchange mechanism. A possible interaction can be expressed in the following way:

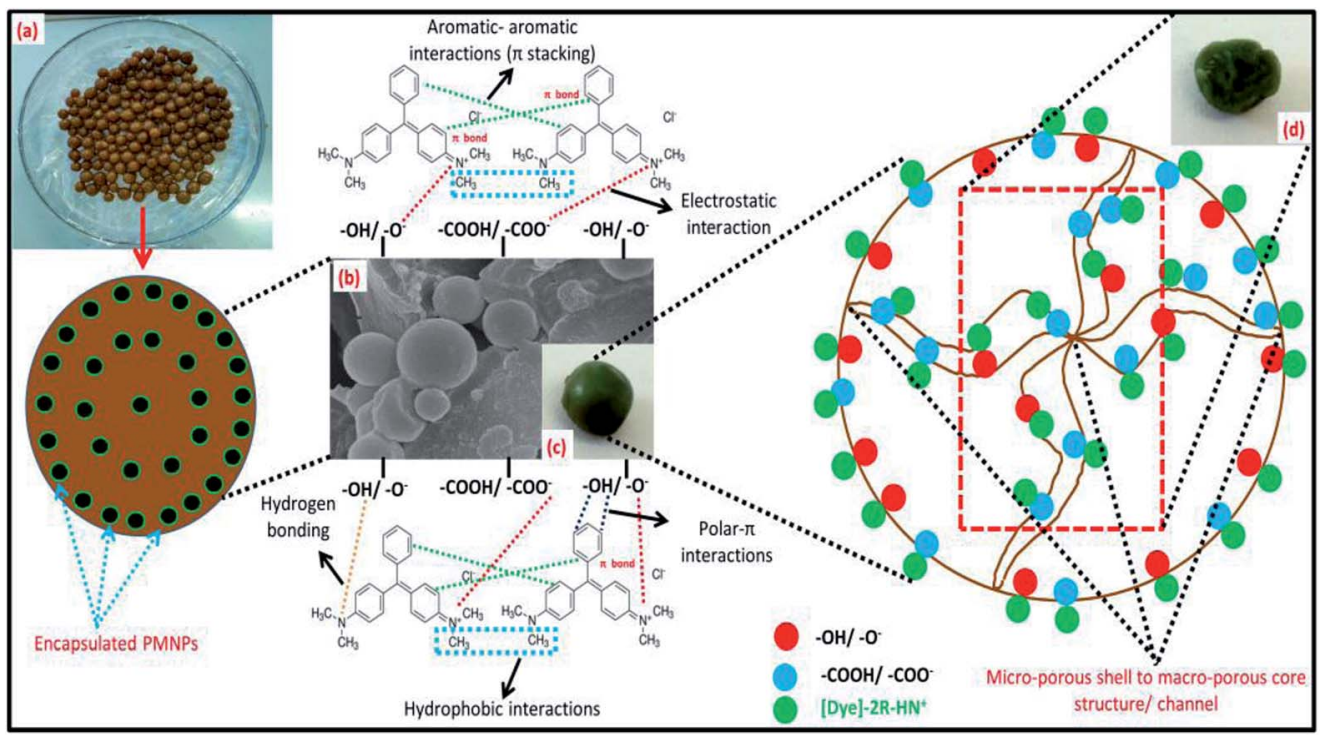

Fig. 17 Proposed adsorptive removal mechanism of cationic malachite green (MG) dye by bio-magnetic membrane capsules (BMMCs) and (a) a real pictorial representation of fabricated BMMCs, (b) SEM images of BMMCs, (c) real pictorial representation of the outer surface of the BMMCs after the sorption of cationic MG dye, and (d) a real pictorial representation of the cross-sectional/inner surface of the BMMCs after the sorption of cationic MG dye for a better understanding. 
Table 8 Comparison of bio-magnetic membrane capsules (BMMCs) with other reported sorbents for the removal of cationic malachite green (MG) dye ${ }^{a}$

\begin{tabular}{|c|c|c|c|}
\hline Cationic dye & Sorbent & $q_{\mathrm{e}}\left(\mathrm{mg} \mathrm{g}^{-1}\right)$ & Reference \\
\hline MG & Chitosan ionic liquid beads & 8.07 & 33 \\
\hline MG & Carboxylate group functionalized multi-walled carbon nanotubes & 11.73 & 34 \\
\hline MG & Wood apple shell (WAS) & 34.56 & 36 \\
\hline MG & Activated carbon derived from Borassus aethiopum flowers & 48.48 & 37 \\
\hline MG & $\mathrm{CoFe}_{2} \mathrm{O}_{4}-\mathrm{SiO}_{2}$ & 75.50 & 23 \\
\hline MG & Rice straw-derived char & 148.7 & 39 \\
\hline MG & Graphene oxide-agarose hydrogel & 186.0 & 40 \\
\hline MG & Organo-HAP & 188.18 & 41 \\
\hline MG & Almond gum & 196.07 & 42 \\
\hline MG & MIL-100(Fe) & 205.0 & 43 \\
\hline MG & $\mathrm{CNF}$ aerogel & 212.7 & 44 \\
\hline MG & Reduced graphene oxide (rGO) & 476.2 & 49 \\
\hline MG & Bio-magnetic membrane capsules (BMMCs) & 500 & Present study \\
\hline MG & Magnetic $\beta$-cyclodextrin-graphene oxide nanocomposites $\left(\mathrm{Fe}_{3} \mathrm{O}_{4} / \beta\right.$-CD/GO) & 740.7 & 50 \\
\hline MG & $\begin{array}{l}\text { Nickel nanoparticles encapsulated in porous carbon and carbon nanotube } \\
\text { hybrids }\end{array}$ & 898 & 51 \\
\hline MG & Calcium-rich biochar (CRB) & 12502 & 52 \\
\hline
\end{tabular}

$$
[\text { Dye }]-2 \mathrm{R}-\mathrm{HN}^{+}+[\mathrm{BMMC}]-\mathrm{OH} \rightarrow[\text { Dye }]-2 \mathrm{R}-\mathrm{HN}^{+}-{ }^{-} \mathrm{O}-
$$$$
[\mathrm{BMMC}]+\mathrm{H}^{+}
$$

and

$$
\begin{gathered}
{[\text { Dye }]-2 \mathrm{R}-\mathrm{HN}^{+}+[\mathrm{BMMC}]-\mathrm{COOH} \rightarrow[\text { Dye }]-2 \mathrm{R}-} \\
\mathrm{HN}^{+}-{ }^{-} \mathrm{OOC}-[\mathrm{BMMC}]+\mathrm{H}^{+}
\end{gathered}
$$

\subsection{Comparison of BMMCs with other sorbents and proposed BMMC based wastewater treatment model}

Finally, compared to other sorbents and/or composites for the removal of cationic MG dye from wastewater, it is obvious that different kinds of adsorbents indicate different characteristics, but it was found that our BMMCs prepared by the encapsulation of green PMNPs had comparatively superior adsorptive performance in terms of adsorptive capacity and removal towards

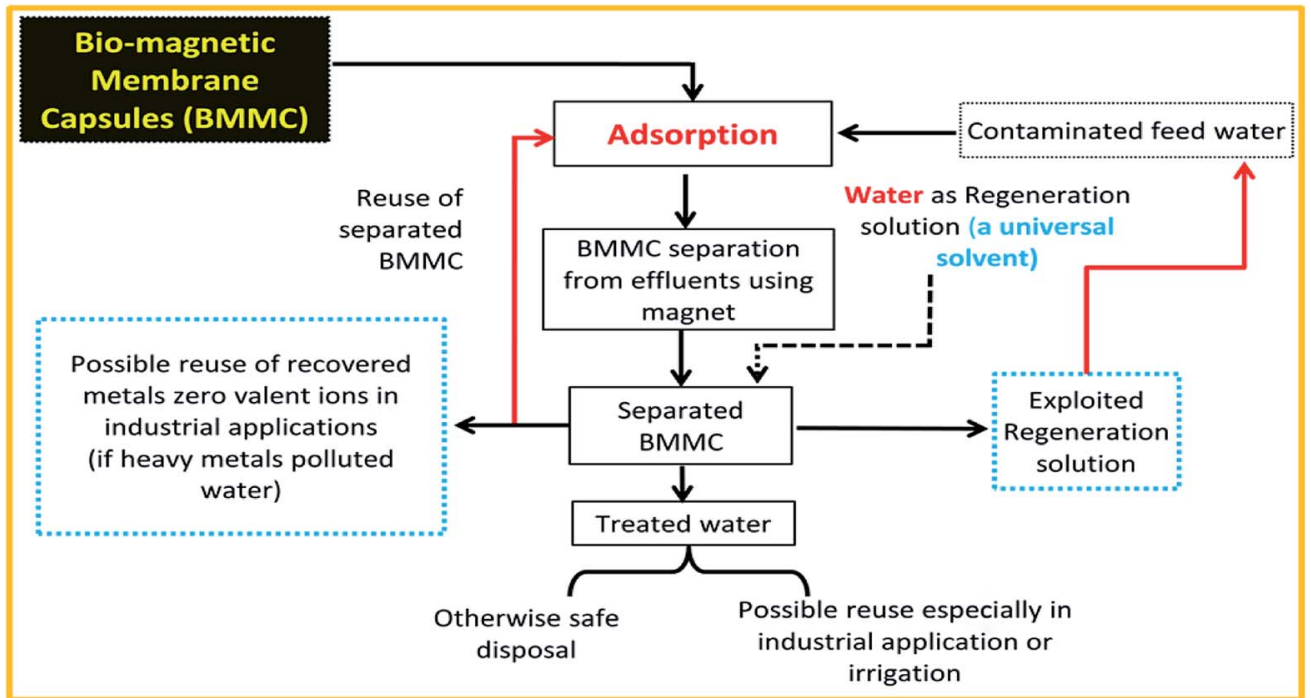

Fig. 18 Proposed conceptual treatment model using bio-magnetic membrane capsules (BMMCs) based on zero-effluent discharge for water/ wastewater containing cationic toxic dyes and heavy metal ions. 
cationic MG toxic dye along with offering capsule regeneration just by using water and better reusability for up to four consecutive treatment cycles (Table 8). Moreover, an ecofriendly fabrication, wide operable $\mathrm{pH}$ range (3-12), rapid and easy magnetic separation from final effluents just by applying a simple hand-held magnet makes BMMCs an attractive candidate/3D composite magnetic sorbent for the treatment of wastewater containing cationic pollutants. It was also anticipated that the fabricated BMMCs could provide broad applications in the fields of green chemistry and environmental engineering. Importantly, this encapsulation technique will assist in resolving PMNP oxidation problems, and the generation of secondary pollution can be controlled along with improving PMNP adsorptive performance and stability for longterm applications. Therefore, inspired by the results obtained from this study, a model of BMMCs based on zero-effluent discharge was consequently proposed (Fig. 18).

\section{Conclusions}

In the present work, novel bio-magnetic membrane capsules (BMMCs) were successfully prepared to control the disintegration of phytogenic magnetic nanoparticles (PMNPs) for the adsorptive removal of cationic toxic MG dye from water. The fabrication, morphology, surface properties and magnetic measurements were inspected via FTIR, powder XRD, SEM, EDX, XPS, VSM and BET techniques. The following are the key findings of the present work:

- PMNPs were smoothly encapsulated into a PVA-SA matrix via intra/inter-molecular hydrogen bonding, which significantly improved the stability against oxidation/disintegration in an aqueous environment.

- SEM analysis indicated that the prepared BMMCs had a micro-porous surface and a macro-porous core morphology.

- Batch adsorption experiments indicated that the prepared BMMCs had an excellent adsorption capacity of up to $500 \mathrm{mg}$ $\mathrm{g}^{-1}$ against MG under optimized operating conditions ( $\mathrm{pH} 6.5$; temp: $25{ }^{\circ} \mathrm{C}$; contact time: $24 \mathrm{~h}$, agitation speed: $100 \mathrm{rpm}$; and adsorbent dosage: $0.02 \mathrm{~g} \mathrm{~L}^{-1}$ ), due to the presence of a large amount of hydrophilic functional groups.

- Moreover, the adsorption isotherm, kinetic, thermodynamic and FTIR results indicated that MG dye is mainly removed via electrostatic interactions and ion-exchange mechanisms, while the regeneration results indicated that some other co-present forces (i.e. hydrogen bonding, hydrophobic interaction and $\pi-\pi$ interaction/stacking-like polar- $\pi$ interactions and aromatic-aromatic interactions $/ \pi$ stacking) were also involved.

- In addition, the prepared BMMCs can be reused for at least four (4) consecutive treatment cycles just by washing with water without apparent leaching leakage of $\mathrm{PMNPs} / \mathrm{Fe}^{0}$, and can be easily separated from aqueous solution within $10 \mathrm{~s}$ just by using a hand-held magnet, due to their superparamagnetic behavior.

Altogether, the fabricated BMMCs indicated a high adsorptive capacity and stability compared to naked/bare PMNPs, which emphasizes the brilliant potential for their practical application in water/wastewater treatment.

\section{Author contributions}

All authors contributed to the analysis of data and the preparation of the manuscript.

\section{Conflicts of interest}

The authors declare no conflict of interest.

\section{Acknowledgements}

This work was supported by the State Key Laboratory of Environmental Criteria and Risk Assessment (No. SKLECRA 2013FP12) and the Shandong Province Key Research and Development Program (2016GSF115040). Meanwhile, the first author would like to give thanks for the financial support from the Chinese Scholarship Council, China (CSC No: 2016GXYO20).

\section{References}

1 I. Ali, C. Peng, Z. M. Khan, I. Naz, M. Sultan, M. Ali, I. A. Abbasi, T. Islam and T. Ye, J. Environ. Manage., 2015, 230, 128-150.

2 I. Ali, C. Peng, I. Naz, Z. M. Khan, M. Sultan, T. Islama and I. A. Abbasi, RSC Adv., 2017a, 7, 40158-40178.

3 I. Ali, C. Peng, T. Ye and I. Naz, RSC Adv., 2018a, 8(16), 88788897.

4 S. Bekin, S. Sarmad, K. Gürkan, G. Keçeli and G. Gürdağ, Sens. Actuators, B, 2014, 202, 878-892.

5 F. G. Thankam, J. Muthu, V. Sankar and R. K. Gopal, Colloids Surf., B, 2013, 107, 137-145.

6 I. Ali, C. Peng and I. Naz, Chin. J. Chem. Eng., 2018b, DOI: 10.1016/j.cjche.2018.03.018.

7 C. F. Huang, A. C. Huang, Y. F. Hsieh, F. J. Chu and T. J. Wan, Water Resources and Industry, 2017, 18, 9-16.

8 E. S. Dragan, Chem. Eng. J., 2014, 243, 572-590.

9 H. S. Samanta and S. K. Ray, Carbohydr. Polym., 2014, 99, 666-678.

10 S. Kahya, E. K. Solak and O. Şanl, Vacuum, 2010, 84(9), 10921102.

11 I. Ali, Z. M. Khan, M. Sultan, M. H. Mahmood, H. U. Farid, M. Ali and A. Nasir, Pol. J. Environ. Stud., 2016, 25(6), 22652273.

12 G. B. Messaoud, L. Sánchez-González, L. Probst, C. Jeandel, E. Arab-Tehrany and S. Desobry, Carbohydr. Polym., 2016, 144, 428-437.

13 I. Ali, Z. M. Khan, C. Peng, I. Naz, M. Sultan, M. Ali, M. H. Mahmood and Y. Niaz, Pol. J. Environ. Stud., 2017b, 26(6), 2431-2444.

14 W. C. Jao, H. C. Chen, C. H. Lin and M. C. Yang, Polym. Adv. Technol., 2009, 20(8), 680-688.

15 I. Ali, C. Peng, Z. M. Khan and I. Naz, J. Basic Microbiol., 2017c, 57, 643-652.

16 Y. Yue, J. Han, G. Han, A. D. French, Y. Qi and Q. Wu, Carbohydr. Polym., 2016, 147, 155-164. 
17 I. Ali, C. Peng, Z. M. Khan, I. Naz and M. Sultan, J. Chem. Technol. Biotechnol., 2018c, 2817-2832.

18 I. Ali, C. Peng, Z. M. Khan, M. Sultan and I. Naz, Arabian J. Sci. Eng., 2018d, 1-15.

19 I. Ali, C. Peng, D. Lin and I. Naz, Green Process. Synth., 2018e, DOI: $10.1515 / \mathrm{gps}-2018-0078$.

20 T. Islam, C. Peng and I. Ali, J. Basic Microbiol., 2018, 58(5), 378-389.

21 A. Akbari, J. Taiwan Inst. Chem. Eng., 2017, 70, 391-400.

22 J. Hoon Kim, J. Jegal, J. Hye Kim, K. H. Lee and Y. Lee, J. Appl. Polym. Sci., 2003, 89(11), 3046-3051.

23 M. Amiri, M. Salavati-Niasari, A. Akbari and T. Gholami, Int. J. Hydrogen Energy, 2017, 42(39), 24846-24860.

24 I. Ali, C. Peng, D. Lin, D. P. Saroj, I. Naz, Z. M. Khan, M. Sultan and M. Ali, J. Environ. Manage., 2019, 234, 273-289.

25 R. Guo, T. Jiao, R. Li, Y. Chen, W. Guo, L. Zhang, J. Zhou, Q. Zhang and Q. Peng, ACS Sustainable Chem. Eng., 2017, 6(1), 1279-1288.

26 Y. Zhang, S. Xu, Y. Luo, S. Pan, H. Ding and G. Li, J. Mater. Chem., 2011, 21(11), 3664-3671.

27 F. Wang, L. Zhang, Y. Wang, X. Liu, S. Rohani and J. Lu, Appl. Surf. Sci., 2017, 420, 970-981.

28 Y. Hong, I. A. Choi, M. Pal, G. Lee, K. M. Nam and W. S. Seo, RSC Adv., 2018, 8(2), 1089-1097.

29 W. G. Liang, C. Yang, G. Q. Wen, W. Wang, X. J. Ju, R. Xie and L. Y. Chu, Appl. Therm. Eng., 2014, 70(1), 817-826.

30 Y. Y. Ling and F. B. M. Suah, J. Environ. Chem. Eng., 2017, 5(1), 785-794.

31 N. A. Dahlan, A. K. Veeramachineni, S. J. Langford and J. Pushpamalar, Carbohydr. Polym., 2017, 173, 619-630.

32 S. Karcher, A. Kornmüller and M. Jekel, Dyes Pigm., 2001, 51(2-3), 111-125.

33 F. Naseeruteen, N. S. A. Hamid, F. B. M. Suah, W. S. W. Ngah and F. S. Mehamod, J. Biol. Macromol., 2018, 107, 1270-1277.

34 M. Rajabi, B. Mirza, K. Mahanpoor, M. Mirjalili, F. Najafi, O. Moradi, H. Sadegh, R. Shahryari-Ghoshekandi, M. Asif, I. Tyagi and S. Agarwal, J. Ind. Eng. Chem., 2016, 34, 130-138.
35 F. Gündüz and B. Bayrak, J. Mol. Liq., 2017, 243, 790-798.

36 A. S. Sartape, A. M. Mandhare, V. V. Jadhav, P. D. Raut, M. A. Anuse and S. S. Kolekar, Arabian J. Chem., 2017, 10, S3229-S3238.

37 S. Nethaji, A. Sivasamy, G. Thennarasu and S. Saravanan, J. Hazard. Mater., 2010, 181(1-3), 271-280.

38 Z. Bekçi, C. Özveri, Y. Seki and K. Yurdakoç, J. Hazard. Mater., 2008, 154(1-3), 254-261.

39 B. H. Hameed and M. I. El-Khaiary, J. Hazard. Mater., 2008, 153(1-2), 701-708.

40 R. Gong, M. Feng, J. Zhao, W. Cai and L. Liu, Bioresour. Technol., 2009, 100(2), 975-978.

41 A. A. El-Zahhar and N. S. Awwad, J. Environ. Chem. Eng., 2016, 4(1), 633-638.

42 F. Bouaziz, M. Koubaa, F. Kallel, R. E. Ghorbel and S. E. Chaabouni, Int. J. Biol. Macromol., 2017, 105, 56-65.

43 S. H. Huo and X. P. Yan, J. Mater. Chem., 2012, 22(15), 74497455.

44 F. Jiang, D. M. Dinh and Y. L. Hsieh, Carbohydr. Polym., 2017, 173, 286-294.

45 Y. Wang, P. Zhang, C. F. Liu and C. Z. Huang, RSC Adv., 2013, 3(24), 9240-9246.

46 Q. Yang, Y. Wang, J. Wang, F. Liu, N. Hu, H. Pei, W. Yang, Z. Li, Y. Suo and J. Wang, Food Chem., 2018, 254, 241-248.

47 A. Liu, W. Zhou, K. Shen, J. Liu and X. Zhang, RSC Adv., 2015, 5(22), 17336-17342.

48 D. Gautam, S. Kumari, B. Ram, G. S. Chauhan and K. Chauhan, J. Environ. Chem. Eng., 2018, 6(4), 3889-3897.

49 K. Gupta and O. P. Khatri, J. Colloid Interface Sci., 2017, 501, 11-21.

50 D. Wang, L. Liu, X. Jiang, J. Yu and X. Chen, Colloids Surf., A, 2015, 466, 166-173.

51 L. Jin, X. Zhao, X. Qian and M. Dong, J. Colloid Interface Sci., 2018, 509, 245-253.

52 L. Dai, W. Zhu, L. He, F. Tan, N. Zhu, Q. Zhou, M. He and G. Hu, Bioresour. Technol., 2018, 267, 510-516. 